\title{
TransCom model simulations of methane: Comparison of vertical profiles with aircraft measurements
}

\author{
Ryu Saito, ${ }^{1}$ Prabir K. Patra, ${ }^{1,2}$ Colm Sweeney, ${ }^{3}$ Toshinobu Machida, ${ }^{4}$ Maarten Krol, ${ }^{5,6}$
} Sander Houweling, ${ }^{6}$ Philippe Bousquet, ${ }^{7}$ Anna Agusti-Panareda, ${ }^{8}$ Dmitry Belikov, ${ }^{4}$ Dan Bergmann, ${ }^{9}$ Huisheng Bian, ${ }^{10}$ Philip Cameron-Smith, ${ }^{9}$ Martyn P. Chipperfield, ${ }^{11}$ Audrey Fortems-Cheiney, ${ }^{7}$ Annemarie Fraser, ${ }^{12}$ Luciana V. Gatti, ${ }^{13}$ Emanuel Gloor, ${ }^{11}$ Peter Hess, ${ }^{14}$ Stephan R. Kawa, ${ }^{10}$ Rachel M. Law, ${ }^{15}$ Robin Locatelli, ${ }^{7}$ Zoe Loh, ${ }^{15}$ Shamil Maksyutov, ${ }^{4}$ Lei Meng, ${ }^{16}$ John B. Miller, ${ }^{3}$ Paul I. Palmer, ${ }^{12}$ Ronald G. Prinn, ${ }^{17}$ Matthew Rigby, ${ }^{17,18}$ and Christopher Wilson ${ }^{11}$

Received 27 September 2012; revised 27 March 2013; accepted 28 March 2013; published 13 May 2013.

[1] To assess horizontal and vertical transports of methane $\left(\mathrm{CH}_{4}\right)$ concentrations at different heights within the troposphere, we analyzed simulations by 12 chemistry transport models (CTMs) that participated in the TransCom- $\mathrm{CH}_{4}$ intercomparison experiment. Model results are compared with aircraft measurements at 13 sites in Amazon/Brazil, Mongolia, Pacific Ocean, Siberia/Russia, and United States during the period of 2001-2007. The simulations generally show good agreement with observations for seasonal cycles and vertical gradients. The correlation coefficients of the daily averaged model and observed $\mathrm{CH}_{4}$ time series for the analyzed years are generally larger than 0.5 , and the observed seasonal cycle amplitudes are simulated well at most sites, considering the between-model variances. However, larger deviations show up below $2 \mathrm{~km}$ for the model-observation differences in vertical profiles at some locations, e.g., at Santarem, Brazil, and in the upper troposphere, e.g., at Surgut, Russia. Vertical gradients and concentrations are underestimated at Southern Great Planes, United States, and Santarem and overestimated at Surgut. Systematic overestimation and underestimation of vertical gradients are mainly attributed to inaccurate emission and only partly to the transport uncertainties. However, large differences in model simulations are found over the regions/seasons of strong convection, which is poorly represented in the models. Overall, the zonal and latitudinal variations in $\mathrm{CH}_{4}$ are controlled by surface emissions below $2.5 \mathrm{~km}$ and transport patterns in the middle and upper troposphere. We show that the models with larger vertical gradients, coupled with slower horizontal transport, exhibit greater $\mathrm{CH}_{4}$ interhemispheric gradients in the lower troposphere. These findings have significant implications for the future development of more accurate CTMs with the possibility of reducing biases in estimated surface fluxes by inverse modeling.

Citation: Saito, R., et al. (2013), TransCom model simulations of methane: Comparison of vertical profiles with aircraft measurements, J. Geophys. Res. Atmos., 118, 3891-3904, doi:10.1002/jgrd.50380.

Additional supporting information may be found in the online version of this article.

${ }^{1}$ Research Institute for Global Change/JAMSTEC, Yokohama, Japan.

${ }^{2}$ Center for Atmospheric and Oceanic Studies, Tohoku University, Sendai, Japan.

${ }^{3}$ NOAA Earth Systems Research Laboratory, Boulder, Colorado, USA.

${ }^{4}$ Center for Global Environmental Research, National Institute for Environmental Studies, Tsukuba, Japan.

${ }^{5}$ Wageningen University and Research Centre, Wageningen, Netherlands.

${ }^{6}$ SRON Netherlands Institute for Space Research, Utrecht, Netherlands. France.

${ }^{7}$ Universite de Versailles Saint Quentin en Yvelines, Gif-sur-Yvette,

Corresponding author: P. K. Patra, Research Institute for Global Change/JAMSTEC, 3173-25 Showa-machi, Yokohama 236-0001, Japan. (prabir@jamstec.go.jp)

(C)2013. American Geophysical Union. All Rights Reserved. 2169-897X/13/10.1002/jgrd.50380

\footnotetext{
${ }^{8}$ European Centre for Medium-Range Weather Forecasts, Reading, UK.

${ }^{9}$ Atmospheric, Earth, and Energy Division, Lawrence Livermore National Laboratory, Livermore, California, USA.

${ }^{10}$ Goddard Earth Sciences and Technology Center, NASA Goddard Space Flight Center, Greenbelt, Maryland, USA.

${ }^{11}$ Institute for Climate and Atmospheric Science, School of Earth and Environment, University of Leeds, Leeds, UK.

${ }^{12}$ School of GeoSciences, University of Edinburgh, Edinburgh, UK.

${ }^{13}$ Divisao de Quimica Ambiental, Insituto de Pesquisas Energeticas e Nucleares, Sao Paulo, Brasil.

${ }^{14}$ Cornell University, Ithaca, New York, USA.

${ }^{15}$ Centre for Australian Weather and Climate Research, CSIRO Marine and Atmospheric Research, Aspendale, Vic, Australia.

${ }^{16}$ Department of Geography and Environmental Studies Program, Western Michigan University, Kalamazoo, Michigan, USA.

${ }^{17}$ Center for Global Change Science, Massachusetts Institute of Technology, Cambridge, Massachusetts, USA.

${ }^{18}$ School of Chemistry, University of Bristol, Bristol, UK.
} 


\section{Introduction}

[2] Methane $\left(\mathrm{CH}_{4}\right)$ is an important greenhouse gas, contributes to photochemical smog formation under polluted conditions by reaction with hydroxyl radical $(\mathrm{OH})$, and is the main source of water vapor in the stratosphere [Graedel and Crutzen, 1993]. Over the last two decades, $\mathrm{CH}_{4}$ simulations have been conducted using three-dimensional global chemistry transport models (CTMs) [e.g., Fung et al., 1991]. Recently, a model intercomparison experiment (TransCom- $\mathrm{CH}_{4}$ ) has been organized with the aim to assess the roles of uncertainties in model transport, surface emissions, and $\mathrm{OH}$ chemistry for simulating global $\mathrm{CH}_{4}$. The first analysis [Patra et al., 2011a] concentrated on background concentrations at the surface and showed overall consistent results across the participating models. However, that analysis was limited to eight surface sites, where simultaneous measurements of $\mathrm{CH}_{4}$, sulfur hexafluoride $\left(\mathrm{SF}_{6}\right)$, and methyl chloroform $\left(\mathrm{CH}_{3} \mathrm{CCl}_{3}\right)$ were available for more than 5 years in the period 1990-2007. Patra et al. [2011a] demonstrated that some models consistently underestimate or overestimate the meridional gradients of all the three species depending on the simulated rate of interhemispheric mixing. Based on $\mathrm{SF}_{6}$ concentration gradients, for two northern (Barrow and Mauna Loa) and two southern (Cape Grim and South Pole) hemispheric sites, the interhemispheric exchange time is estimated to be in the range of 1.0-1.8 years for the suites of TransCom- $\mathrm{CH}_{4}$ models.

[3] How the simulated zonal or meridional gradient varies with altitude for the long-lived species, however, has not been studied in detail yet. Nakazawa et al. [1991] suggested that the meridional gradient in the carbon dioxide $\left(\mathrm{CO}_{2}\right)$ concentration in the upper troposphere is significantly smaller compared to that near the Earth's surface. Stephens et al. [2007] showed that the $\mathrm{CO}_{2}$ vertical gradients between the former suites of TransCom (Level 3) models, mostly developed pre-2000, varies widely due to the difference in vertical mixing rate. Note here that the interpretation of model transport has become complex using $\mathrm{CO}_{2}$ due to strong seasonal variation in surface fluxes; strong source due to heterotrophic respiration in addition to fossil fuel emissions in the winter, and strong sink dominated by photosynthetic uptake in the summer [e.g., Miyazaki et al., 2008]. The strong diurnal cycle in $\mathrm{CO}_{2}$ fluxes also complicate flux-transport interaction vertically, particularly over the land region [Law et al., 2008]. Because $\mathrm{CH}_{4}$ sources dominate over the soil uptake on the surface in all seasons, and the atmospheric lifetime of $\mathrm{CH}_{4}$ is about 10 years [Patra et al., 2011a], the TransCom model intercomparison for $\mathrm{CH}_{4}$ vertical profiles would be relatively straightforward for interpreting the transport and emission model errors. Advantages of using constituents (e.g., $\mathrm{CH}_{4}$ ) with net sources on the Earth's surface over that of $\mathrm{CO}_{2}$ to diagnose model transport have been shown over the South Asian region during the season of strong $\mathrm{CO}_{2}$ uptake by the terrestrial ecosystem [Patra et al., 2011b].

[4] Analyses of $\mathrm{CH}_{4}$ vertical profiles using CTMs have been limited to single model [Bergamaschi et al., 2009] and for specific regions [Beck et al., 2012] and are proven to be useful for validating surface emissions. The TransCom- $\mathrm{CH}_{4}$ data base includes simulated vertical profiles by 17 CTMs, which can be compared to data from several aircraft measurement programs that have been carried out during the last decade [Tans et al., 1996; Machida et al., 2001; Gatti et al., 2010]. The latitudepressure distributions of zonal mean simulation results show that $\mathrm{CH}_{4}$ concentrations, within the troposphere, decrease with altitude in the Northern Hemisphere (NH) and increase with altitude in the Southern Hemisphere (SH) [Patra et al., 2011a]. Both the vertical and meridional gradients exhibit seasonal dependency in relation to seasonality in transport, surface emissions, or chemical loss. However, this conjecture is based only on the model intercomparison, without comparison with observations. Thus, an evaluation of the modeling results with aircraft observations will likely improve our understanding of $\mathrm{CH}_{4}$ transport mechanisms of vertical and interhemispheric exchanges in the troposphere.

[5] The purpose of this study is to evaluate the simulated $\mathrm{CH}_{4}$ concentrations using aircraft measurements. The model-observation difference depends on uncertainties in surface fluxes, model transport, and chemistry. We assess the flux and transport dependence of the model-observation differences using vertical profiles over a variety of surface conditions and transport regimes, e.g., wetlands in Siberia, tropical rainforests in Amazon, boreal forests of North America, and the marine environment. In the next sections, we briefly describe the model simulation scenarios and the aircraft measurement programs, followed by results and discussions. Some conclusions are given in section 4 .

\section{Models and Measurements}

\subsection{Simulation Concentrations}

[6] The institutes participating in the TransCom- $\mathrm{CH}_{4}$ experiment produced global $\mathrm{CH}_{4}$ distribution using 13 models and four variants with different spatial resolutions and $\mathrm{OH}$ distributions. The CTM simulation outputs include $\mathrm{CH}_{4}$ vertical profiles over various sites for a decadal period (1992-2007) with a 1 or $3 \mathrm{~h}$ time interval, for six $\mathrm{CH}_{4}$ tracers that used different surface emission scenarios. A detailed description of the TransCom- $\mathrm{CH}_{4}$ experiment is documented in Patra et al. [2011a]. In this study, we use $\mathrm{CH}_{4}$ profiles simulated by 12 CTMs (Table 1), namely, the ACTM (atmospheric general circulation model-based CTM) [Patra et al., 2009a, 2009b], CAM (Community Atmosphere Model) [Gent et al., 2009], CCAM (ConformalCubic Atmospheric Model) [Law et al., 2006], GEOS-Chem (Goddard Earth Observing System (GEOS) meteorologydriven CTM) [Fraser et al., 2011], IFS (Integrated Forecasting System) [www.ecmwf.int/research/ifsdocs/CY36r1/ index.html], IMPACT_1×1.25 (Integrated Massively Parallel Atmospheric Chemical Transport) [Rotman et al., 2004], LMDZ (Laboratoire de Météorologie Dynamique-Zoom, version 4) [Hourdin et al., 2006], MOZART (Model for Ozone and Related Chemical Tracers. version 4) [Emmons et al., 2010], NIES08i (NIES CTM. version 2008 isentropic) [Belikov et al., 2011], PCTM (Parameterized CTM) [Kawa et al., 2004; Bian et al., 2006], TM5_1×1 (Transport Model, version 5) [Krol et al., 2005], and TOMCAT CTM [Chipperfield, 2006].

[7] These selected models used reanalyzed meteorology for simulating synoptic and shorter time scale ( $<7$ days) variations in the observed time series. The newly participating 
SAITO ET AL.: TRANSCOM-CH 4 MODELING OF AIRCRAFT OBSERVATIONS

Table 1. List of the CTMs Used in This Study (See Text for Further Details) and Basic Model Features

\begin{tabular}{|c|c|c|c|c|}
\hline Model Name & Contributing Institute & Vertical Levels & Horizontal Resolution & Source of Meteorology \\
\hline ACTM & RIGC & $67 \sigma$ & $\sim 2.8 \times 2.8^{\circ}$ & NCEP2; U, V, T; SST \\
\hline CAM & $\mathrm{CU}$ & $28 \sigma$ & $2.5 \times \sim 1.9^{\circ}$ & NCEP/NCAR \\
\hline CCAM & CSIRO & $18 \sigma$ & $\sim 220 \mathrm{~km}$ & NCEP; U, V; SST \\
\hline GEOS-Chem & UoE & $30 / 47 \eta$ & $2.5 \times 2.0^{\circ}$ & NASA/GSFC/GEOS4/5 \\
\hline IFS & ECMWF & $60 \eta$ & $0.7 \times 0.7^{\circ}$ & ECMWF, ERA-interim \\
\hline IMPACT_ $1 \times 1.25$ & LLNL & $55 \eta$ & $1.25 \times 1.0^{\circ}$ & NASA/GSFC/GEOS4 \\
\hline LMDZ & LSCE & $19 \eta$ & $3.75 \times 2.5^{\circ}$ & ECMWF; U, V, T; SST \\
\hline MOZART & MIT & $28 \sigma$ & $\sim 1.8 \times 1.8^{\circ}$ & NCEP/NCAR \\
\hline NIES08i & NIES & $32 \sigma-\theta$ & $2.5 \times 2.5^{\circ}$ & JCDAS, ERA-interim-PBL \\
\hline РСТМ & GSFC & $58 \eta$ & $1.25 \times 1.0^{\circ}$ & NASA/GSFC/GEOS5 \\
\hline TM5_1 $1 \times 1$ & SRON & $25 \eta$ & $1.0 \times 1.0^{\circ}$ & ECMWF, ERA-interim \\
\hline TOMCAT & UoL & $60 \eta$ & $\sim 2.8 \times 2.8^{\circ}$ & ECMWF, ERA-40/interim \\
\hline
\end{tabular}

IFS model is based on a semi-Lagrangian semiexplicit version of the European Centre for Medium-Range Weather Forecasts (ECMWF) spectral model (i.e., Eulerian vorticity-divergence configuration). The IFS model is run at the $0.7^{\circ} \times 0.7^{\circ}$ horizontal resolution, finest among all the participating models. The IFS model simulations of $\mathrm{SF}_{6}$ and $\mathrm{CO}_{2}$ has been found satisfactory in the TransCom continuous experiment [Law et al., 2008].

[8] Five models, namely, ACCESS (The Australian Community Climate and Earth-System Simulator) [Corbin and Law, 2011] driven by climatological meteorology, ACTM_OH (OH sensitivity run of ACTM), GEOSChem_DOH (OH sensitivity run), IMPACT (low-resolution version), and TM5 (low-resolution version), are excluded from main discussions of this analysis. For the control simulations, three-dimensional $\mathrm{OH}$ fields at monthly mean time intervals, based on Spivakovsky et al. [2000], have been prescribed in the TransCom-CH4 protocol. Two of the models (ACTM and GEOS-Chem) repeated their TransCom runs with the same resolution and meteorology but with different $\mathrm{OH}$ fields. For both models, the vertical profile gradient was similar in the two different runs. The IMPACT and TM5 models repeated their TransCom runs using different horizontal resolution (implicitly different meteorology). For both models, we find relatively large differences, greater than the differences between different models, in some seasons. No clear distinction can be made whether the higher- or lower-resolution version of the

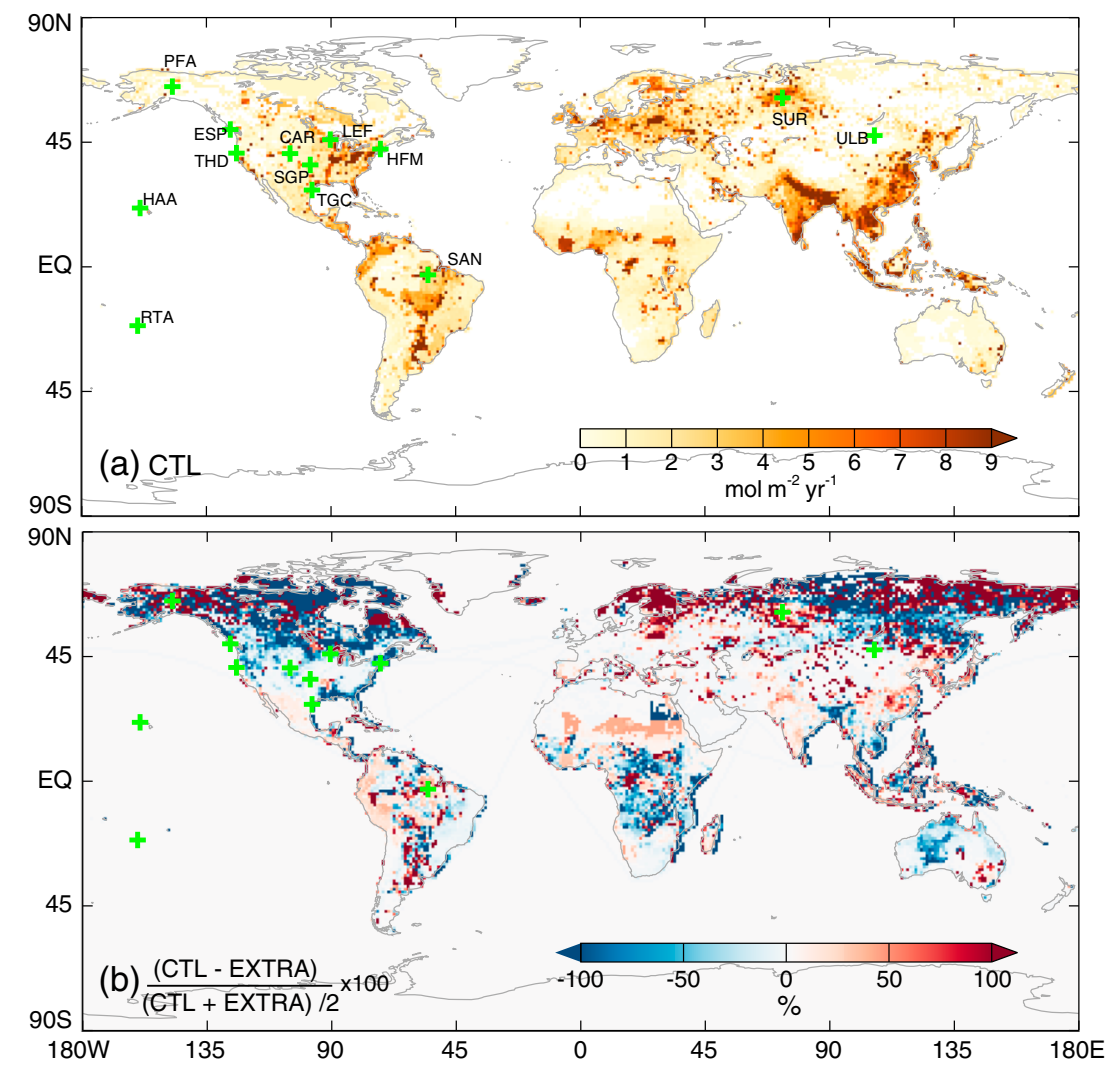

Figure 1. (a) Sampling locations for the aircraft measurements are overplotted on the map showing intensity of the annual mean $\mathrm{CH}_{4}$ emission for the CTL flux. (b) Differences in emission distributions CTL and EXTRA. 
SAITO ET AL.: TRANSCOM-CH 4 MODELING OF AIRCRAFT OBSERVATIONS

Table 2. Site Details of the Aircraft Measurements Used in This Study ${ }^{\mathrm{a}}$

\begin{tabular}{lccccc}
\hline Site & Location & Latitude & Longitude & Above Mean Sea Level (m) & Period \\
\hline PFA & Poker Flat & $65.1^{\circ} \mathrm{N}$ & $147.3^{\circ} \mathrm{W}$ & $1200-7400$ & $2001-2007$ \\
SUR & Surgut & $61.0^{\circ} \mathrm{N}$ & $73.0^{\circ} \mathrm{E}$ & $500-7000$ & $300-5500$ \\
ESP & Estevan Point & $49.6^{\circ} \mathrm{N}$ & $126.4^{\circ} \mathrm{W}$ & $1500-6000$ & $2001-2007$ \\
ULB & Ulaanbaatar & $47.4^{\circ} \mathrm{N}$ & $106.2^{\circ} \mathrm{E}$ & $600-4000$ & $2002-2007$ \\
LEF & Park Falls & $45.9^{\circ} \mathrm{N}$ & $90.3^{\circ} \mathrm{W}$ & $600-7700$ & $2007-2007$ \\
HFM & Harvard Forest & $42.5^{\circ} \mathrm{N}$ & $72.2^{\circ} \mathrm{W}$ & $300-7700$ & $2001-2007$ \\
THD & Trinidad Head & $41.1^{\circ} \mathrm{N}$ & $124.2^{\circ} \mathrm{W}$ & $2100-8700$ & $2003-2007$ \\
CAR & Briggsdale & $40.9^{\circ} \mathrm{N}$ & $104.8^{\circ} \mathrm{W}$ & $170-4900$ & $2001-2007$ \\
SGP & Southern Great Plains & $36.8^{\circ} \mathrm{N}$ & $97.5^{\circ} \mathrm{W}$ & $300-7700$ & $2006-2007$ \\
TGC & Sinton & $27.7^{\circ} \mathrm{N}$ & $96.9^{\circ} \mathrm{W}$ & $300-7700$ & $2003-2007$ \\
HAA & Molokai Island & $21.2^{\circ} \mathrm{N}$ & $159.0^{\circ} \mathrm{W}$ & $150-5200$ & $2001-2007$ \\
SAN & Santarem & $2.9^{\circ} \mathrm{S}$ & $55.0^{\circ} \mathrm{W}$ & $300-6100$ & $2001-2005$ \\
RTA & Rarotonga & $21.3^{\circ} \mathrm{S}$ & $159.8^{\circ} \mathrm{W}$ & & $2001-2007$ \\
\hline
\end{tabular}

${ }^{\mathrm{a}}$ The Surgut site is operated by NIES, and all other sites are by the NOAA/ESRL.

models is better for these two models (see Figure S1 in the supporting information). However, earlier analysis has shown that the higher-resolution version of TM5 performs better than its coarser version for the interhemispheric gradients of $\mathrm{SF}_{6}, \mathrm{CH}_{4}$, and $\mathrm{CH}_{3} \mathrm{CCl}_{3}$ near the Earth's surface [Patra et al., 2011a].

[9] We analyzed $\mathrm{CH}_{4}$ tracers simulated using (1) the control emission scenario (CTL) (Figure 1) that combined seasonally varying natural sources (CYC NAT; major components being the emissions from biomass burning and wetlands) [see Fung et al., 1991] and interannually varying anthropogenic emissions (ANT_IAV; based on EDGAR3.2) [see Olivier and Berdowski, 2001; Patra et al., 2009a for details] and (2) the EXTRA flux, in which interannually varying biomass burning emissions are based on GFEDv3 [van der Werf et al., 2006] and wetland emissions are from the VISIT terrestrial ecosystem model [Ito and Inatomi, 2012]. Based on our experiences in Patra et al. [2011a], these two tracers are sufficient to evaluate the differences in the simulations caused by the emission distribution and strength. The CTL and EXTRA emissions differ by more than $100 \%$ over some of the regions (Figure 1b). To remove systematic offsets between the CTM simulations, the decadal mean concentrations in the altitude range of 2-6 km over Hawaii (HAA) is subtracted from the simulation results. This implies that the horizontal gradients between sites can be studied in reference to Hawaii, but the offset treatment does not affect the determination of vertical gradients or other parts of analysis. For all statistical calculations, the model values are sampled at the time and location of the observations. Model values, between the vertical layers below and above their respective coordinates, are linearly interpolated to measurement height.

\subsection{Aircraft Measurements}

[10] Vertical $\mathrm{CH}_{4}$ profiles have been measured using small aircraft by the National Oceanic and Atmospheric Administration (NOAA) Earth System Research Laboratory (ESRL) at sites in North America and the Pacific (www.esrl. noaa.gov/gmd/ccgg/aircraft/index.html), by the National Institute for Environmental Studies (NIES) at a site in Siberia [Machida et al., 2001], and by NOAA/ESRL in collaboration with Instituto de Pesquisas Energéticas e Nucleares at sites in Amazon [Gatti et al., 2010]. The site names are listed in Table 2, and their locations are plotted with green symbols on a global $\mathrm{CH}_{4}$ emission map in Figure 1a. Air samples are collected using aircraft in the altitudes from the Earth's surface up to 4-10 km depending on the site (Table 2). The aircraft measurements are conducted a few times a month with measurements continuing to the present for all sites, except for Amazon (SAN), where they terminated in 2005. The observation period for each site overlapping with our analysis period is shown in Table 2. Only 2 of the 13 sites are located in the Southern Hemisphere, and 8 of the 11 sites in Northern Hemisphere are located in and around the North American continent. Thus, our analysis of vertical and horizontal gradients does not cover the globe as uniformly as desired for evaluating vertical and horizontal gradients in $\mathrm{CH}_{4}$ and other trace gases.

[11] The samples collected over Surgut, Russia, are analyzed using gas chromatography (Agilent 5890, Agilent Technologies, Inc.) equipped with a flame ionization detector (GC-FID) calibrated against the NIES-94 $\mathrm{CH}_{4}$ scale. The analytical precision of the GC-FID for the $\mathrm{CH}_{4}$ concentration was estimated to be less than $2.0 \mathrm{ppb}$. The NIES-94 $\mathrm{CH}_{4}$ scale is higher than the WMO (NOAA-04) scale by $3.5-4.6 \mathrm{ppb}$ in the concentration range of $1750-1840 \mathrm{ppb}$ [Zhou et al., 2009]. To account for the calibration scale difference, an average value of $4 \mathrm{ppb}$ is subtracted from the measurements over Surgut.

[12] The NOAA ESRL aircraft measurements are made by collecting air samples in $0.7 \mathrm{~L}$ silicate glass flasks at biweekly to monthly intervals at about 16 sites on a regular basis and on campaign mode over Santarem, Brazil (Table 2). Air samples are collected using a turboprop aircraft in the altitude range of about $500 \mathrm{~m}$ to $8 \mathrm{~km}$. $\mathrm{CH}_{4}$ is measured by GC-FID at accuracy of $\pm 1.2 \mathrm{ppb}$. The concentrations are reported at the absolute calibration scale of NOAA-04 that is maintained as the WMO standard [Dlugokencky et al., 2005].

\section{Results and Discussions}

[13] We compare the CTM simulation results with the aircraft measurements to understand the differences between the models and evaluate performance of the models in comparison with measurements during the analysis period of 2001-2007. 
ACTM CAM CCAM IFS GEOS-ChemIMPACT_1

(a) PFA, 2007

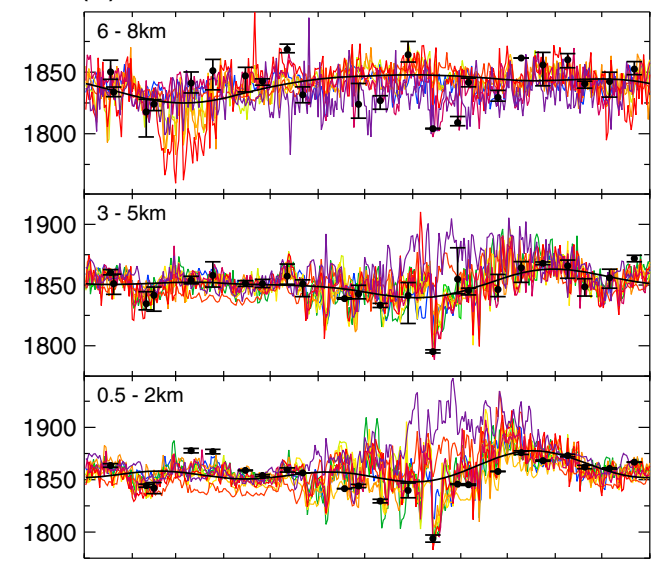

(c) ULB, 2007

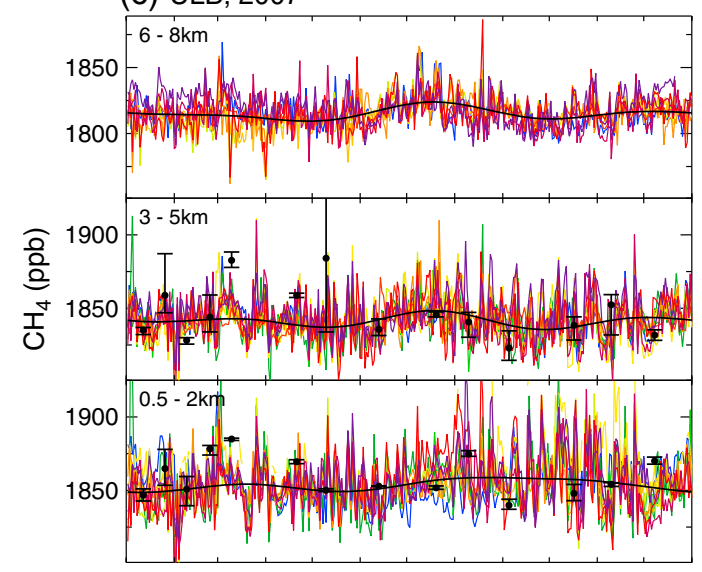

(e) TGC,2005

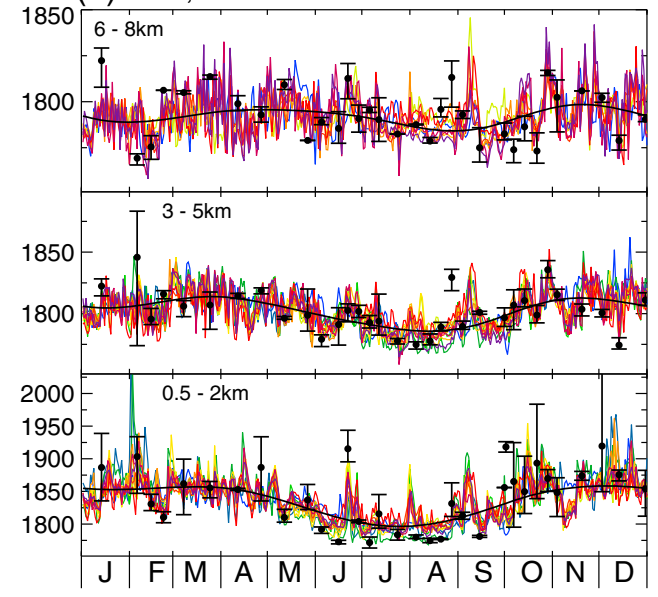

LMDZ MOZART NIES-08i PCTM TM5_1TOMCAT Obs.

\section{(b) SUR, 2005}

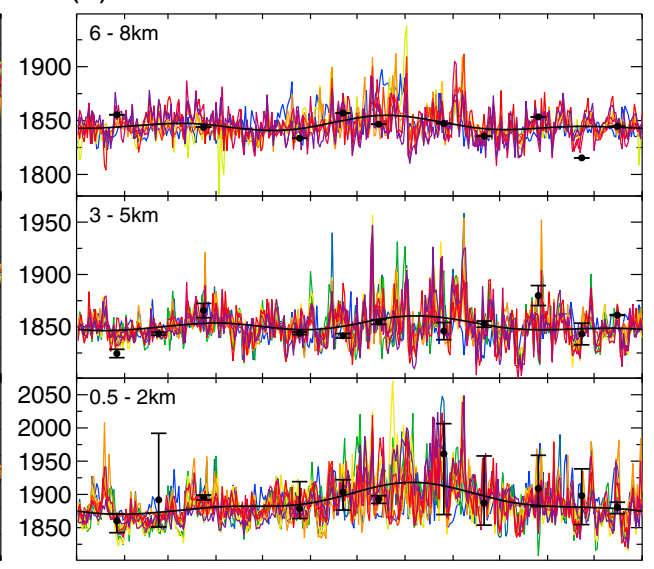

(d) LEF,2005

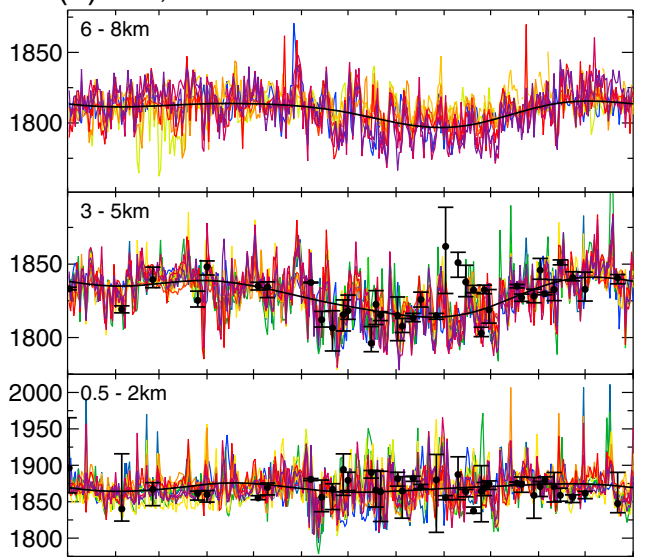

(f) HAA, 2003

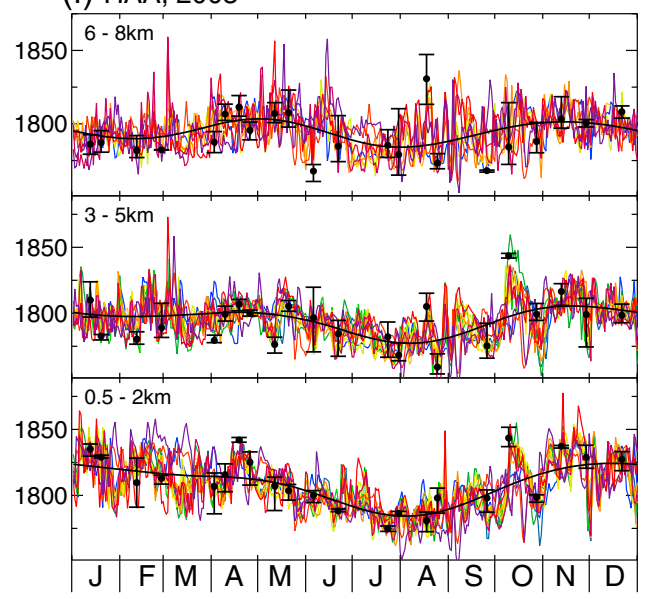

Figure 2. Seasonal variations of the observed (black dots with error bar) and simulated (color lines; see legends at the top; continuous at daily intervals) $\mathrm{CH}_{4}$ concentrations are shown for a comparison at selected sites (time period differs based on data availability at sites, and $y$ axis range differs to show detailed variability). The error bars show the $1 \sigma$ standard deviation of all data within a selected height range. Smooth black lines present fitted curves (three harmonics) to the average seasonal cycle for all the models. The results for each site are averaged over three different altitude ranges, representing lower troposphere $(0.5-2 \mathrm{~km})$, middle troposphere $(3-5 \mathrm{~km})$, and upper troposphere $(6-8 \mathrm{~km})$.

\subsection{Seasonal and Daily Variations at Different Heights}

[14] Figure 2 shows the observed and simulated time series of $\mathrm{CH}_{4}$ concentration for 2007 for three different height ranges $(0.5-2,3-5$, and $6-8 \mathrm{~km})$ and six sites. Information on seasonal cycles is sometimes difficult to extract from the measurements given the irregularity in data coverage and gaps in the time series (black dots). For better 
Table 3. Measured and Model Simulated Seasonal Cycle Amplitudes of $\mathrm{CH}_{4}$ at Two Altitude Ranges ${ }^{\mathrm{a}}$

\begin{tabular}{lccccccc}
\hline & \multicolumn{3}{c}{$1-3 \mathrm{~km}$} & & \multicolumn{3}{c}{$3-5 \mathrm{~km}$} \\
\cline { 3 - 4 } \cline { 6 - 8 } & & \multicolumn{2}{c}{ Model } & & & & \multicolumn{2}{c}{ Model } \\
\cline { 3 - 4 } \cline { 6 - 8 } Sites & Observed & Mean & SD & & Observed & Mean & SD \\
\hline PFA & 28.9 & 31.6 & 7.5 & & 28.9 & 24.6 & 4.7 \\
SUR & 56.4 & 49.9 & 16.9 & & 39.5 & 18.6 & 5.1 \\
ESP & 34.9 & 40.1 & 4.5 & & 33.4 & 24.2 & 6.9 \\
ULB & 35.0 & 20.5 & 6.7 & & 35.2 & 16.2 & 3.3 \\
LEF & 32.4 & 27.5 & 6.5 & & 32.9 & 30.2 & 5.1 \\
HFM & 48.9 & 26.8 & 7.0 & & 34.6 & 28.8 & 6.6 \\
THD & 42.3 & 38.8 & 4.7 & & 29.2 & 29.3 & 6.2 \\
CAR & - & - & - & & 34.7 & 30.0 & 8.8 \\
SGP & 73.9 & 52.1 & 14.7 & & 38.7 & 32.3 & 5.7 \\
TGC & 89.0 & 65.1 & 13.7 & & 32.9 & 26.1 & 7.0 \\
HAA & 36.9 & 44.0 & 8.6 & & 30.2 & 34.8 & 4.5 \\
SAN & 86.7 & 46.9 & 10.0 & & 68.6 & 33.3 & 7.2 \\
RTA & 26.4 & 28.3 & 12.9 & & 35.1 & 25.2 & 6.8 \\
\hline
\end{tabular}

${ }^{\mathrm{a}}$ Model results are given as mean and $1 \sigma$ standard deviations (individual model results are available in Table S1).

clarity, we only show multimodel mean seasonal cycles (black line), which are created by fitting a curve (three harmonics) to the afternoon (1200-1600 h local time) mean time series. This method ensures unambiguous identification of the peaks and troughs in the simulated seasonal cycles of $\mathrm{CH}_{4}$, which is otherwise not well defined due to large data gaps at some of the observation sites. The amplitude and phase of the simulated seasonal cycles are similar for most models, e.g., except TOMCAT, at the northernmost site (PFA). Although the synoptic and daily scale variations show differences between the modeling results, we find that the observed seasonal cycle matches the models within $1 \sigma$ standard deviations at most sites (Table 3). The observed seasonal cycle is significantly different from the model mean seasonal cycles for some of the continental/coastal sites (ULB, HFM, TGC, and SAN) at 1-3 km height, where the uncertainties in both surface emissions and model transport are greater compared to those at the remote marine site. The synoptic variations (2-10 day) are consistent between models (correlation coefficients generally greater than 0.5; Table S1), indicating similarities in reanalyzed meteorological parameters used in the models. While the behavior of seasonal cycles depends on temporally varying regional emissions and seasonality in zonal mean $\mathrm{OH}$ radical, the synoptic variations in $\mathrm{CH}_{4}$ are produced by regional patterns of emissions and model transport variability at the synoptic time scale. Therefore, we conclude that the synoptic transport and $\mathrm{CH}_{4}$ emission distribution are fairly well represented in all models.

[15] The peak-to-trough seasonal cycle amplitude at 1-3 and $3-5 \mathrm{~km}$ height ranges for SAN, TGC, SGP, and SUR are relatively large compared with the other sites (Tables 3 and $\mathrm{S} 1$ ). Greater daily $\mathrm{CH}_{4}$ variations during summer are simulated at SUR, PFA, LEF, and ULB near the surface, coinciding with the seasonal maximum of $\mathrm{CH}_{4}$, and are thought to be caused by the increase in surface emissions in summer and the seasonally varying dynamics associated with the planetary boundary layer (BL) height as well as cumulus convection. On the other hand, troughs of the multimodel mean seasonal cycles at TGC, HAA, and the other remote sites sampling background air show lower variability during the boreal summer months, coinciding with the seasonal minimum of $\mathrm{CH}_{4}$ in the troposphere, except for RTA. In general, the seasonal amplitudes in the lower troposphere are similar to or larger than those in the upper troposphere. The seasonal amplitude at the northern central Pacific site HAA decreases from 36.9 to $30.2 \mathrm{ppb}$ with altitude, whereas the seasonal amplitude at the southern central Pacific site RTA increases from $26.4 \mathrm{ppb}$ at $1-3 \mathrm{~km}$ to $35.1 \mathrm{ppb}$ at $3-5 \mathrm{~km}$ (Table 3). Throughout the Northern Hemisphere, the amplitude weakens upward as the emission signal from the lower troposphere propagates to the middle/ upper troposphere. This weakening is especially remarkable at TGC (Figure 2e), where the $\mathrm{CH}_{4}$ seasonal cycle amplitude at the $6-8 \mathrm{~km}$ range is reduced to $11 \%$ of that at $0.5-2 \mathrm{~km}$ (all model average of $79 \mathrm{ppb}$ ). On average, the amplitude decreased only marginally at ULB PFA, ESP, and LEF, while at other sites, the amplitude decreased between $30 \%$ and $60 \%$ at $6-8 \mathrm{~km}$ compared to that at $0.5-2 \mathrm{~km}$. Note here that the anthropogenic or biogenic emissions around the Mongolian site ULB is among the lowest observed over the land regions, while PFA, ESP, and LEF are located around the regions of strong $\mathrm{CH}_{4}$ emissions during the boreal summer.

[16] One unusual feature among the seasonal cycles is observed as an increase in $\mathrm{CH}_{4}$ at $6-8 \mathrm{~km}$ height over SUR $\left(73^{\circ} \mathrm{E}, 61^{\circ} \mathrm{N}\right)$ during May-July. The timing of this peak in June-July at $6-8 \mathrm{~km}$ is ahead of the seasonal peak seen near the surface $(0.5-2 \mathrm{~km})$ in July-August, and there is almost no seasonal variation in the $3-5 \mathrm{~km}$ altitude. An examination of $\mathrm{CH}_{4}$ longitude-pressure cross sections (latitude range: $60^{\circ} \mathrm{N}-65^{\circ} \mathrm{N}$; Figure S2) suggests that the high $\mathrm{CH}_{4}$ over SUR during the late spring/early summer is transported from Western Europe. Air masses carrying the signature of European emissions are lifted over the Ural mountain range $\left(57^{\circ} \mathrm{E}, 51^{\circ} \mathrm{N}\right.$ to $\left.66^{\circ} \mathrm{E}, 68^{\circ} \mathrm{N}\right)$ and are subsequently transported to Siberia, Mongolia, and as far as western North America by the prevalent westerly winds, as suggested by the longitude-pressure cross sections of $\mathrm{CH}_{4}$ concentrations (Figure S2). The $\mathrm{CH}_{4}$ peak near the surface is coincident with the seasonal high in emissions from the wetlands in the Siberian region.

\subsection{Vertical Profiles}

[17] Figure 3 shows the seasonal mean vertical $\mathrm{CH}_{4}$ profiles at SUR, TGC, HAA, and SAN with the CTL fluxes during boreal winter (January-March: JFM) and summer (July-September: JAS). The modeled (color lines) and observed (black dots with horizontal bars) vertical profile variations with altitude agree well, inside the standard deviation (black bars) of the seasonal variation of the observed $\mathrm{CH}_{4}$ concentrations.

[18] The simulated vertical profiles at SAN show larger differences between models (a spread of $50 \mathrm{ppb}$ at all altitudes) and with measurements. Due to sparse measurements at some of the sites, e.g., SAN, the significance of modelobservation differences cannot be assessed here, and the altitude range is limited to below $4 \mathrm{~km} . \mathrm{CH}_{4}$ concentrations near the surface are affected by biospheric or anthropogenic activities (including biomass burning) as well as meteorological conditions. For example, clear synoptic variability is observed near the surface at TGC during the JAS months as the site is either under the influence of marine air from 
SAITO ET AL.: TRANSCOM-CH 4 MODELING OF AIRCRAFT OBSERVATIONS

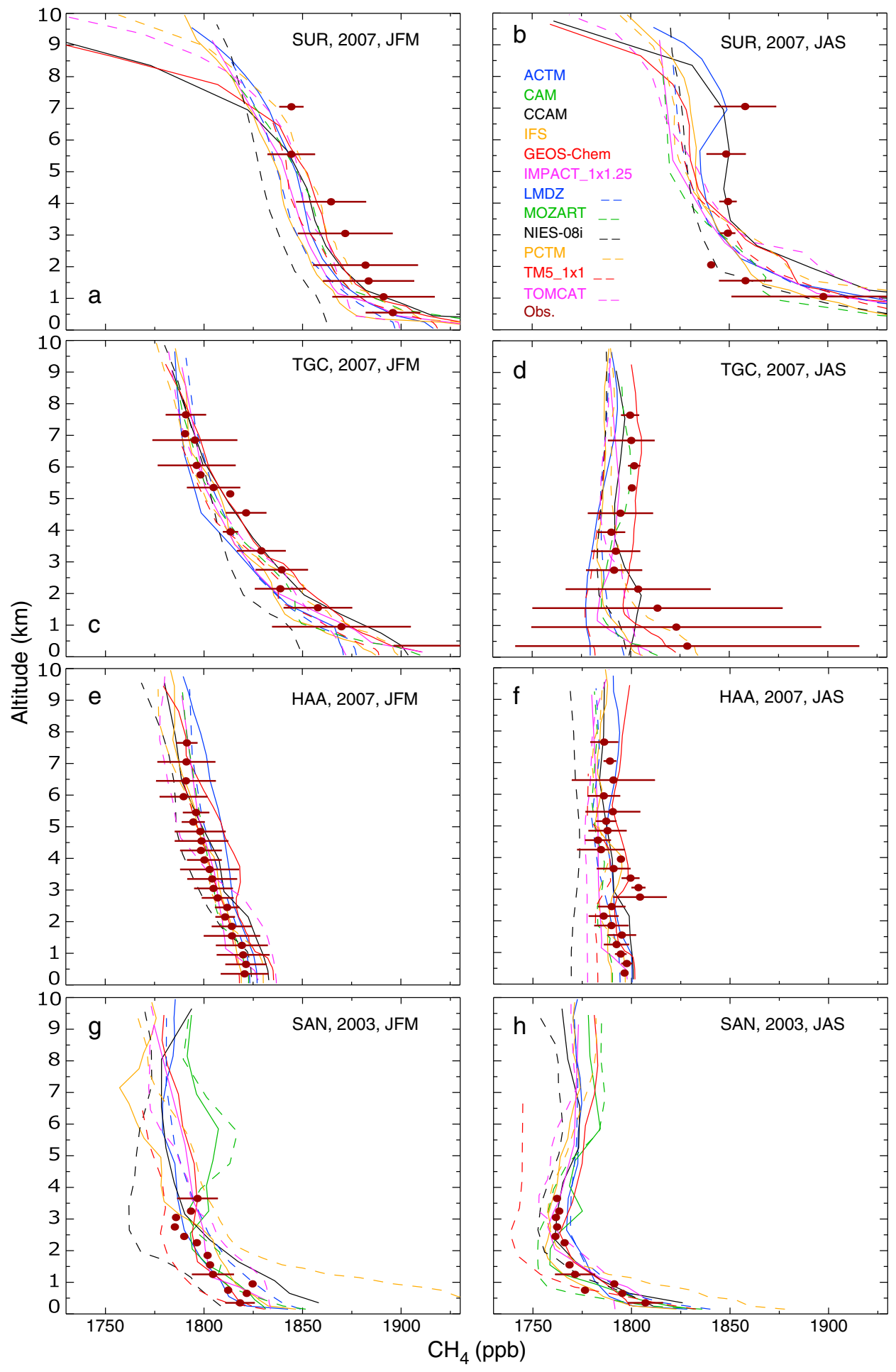

Figure 3. (symbol) Observed and (lines) simulated $\mathrm{CH}_{4}$ vertical profiles at (top row) SUR, (second row from top) HAA, (third row from top) TGC, and (bottom row) SAN for (left) January-March and (right) July-September. Horizontal bars for the 3 months mean measurements present a $1 \sigma$ standard deviation. Results for 2005 and 2007 at more number of sites are shown in Figure S3 (observations at SAN are available only in 2003).

the Atlantic Ocean from the southeast (seen as relatively low concentrations) or from regional emission hot spots around the Gulf of Mexico. During the JFM months, winds are predominantly southwesterly, and the TGC site is under the influence of emissions in Mexico and southwestern United States. Thus, the concentrations are relatively stable (lower variability), and the average values are higher by about $50 \mathrm{ppb}$ in JFM months than those in the JAS months. 
This is due to slower chemical loss of $\mathrm{CH}_{4}$ by $\mathrm{OH}$ in JFM compared to the JAS months in this latitude band.

[19] At SUR, except below $2 \mathrm{~km}$, the simulated results are generally lower than the observed $\mathrm{CH}_{4}$ concentrations during both seasons. A more contrasting feature is observed in the JAS season when the measurements show slightly increasing or fairly constant $\mathrm{CH}_{4}$ concentration between 2-3 and 7-8 km at SUR (and also at TGC). Such elevated levels of gases in the upper troposphere (7-8 km altitude), with emissions only on the Earth's surface, occur frequently in the presence of deep cumulus convection [e.g., Patra et al., 2009b] (refer also to Figure S2 for the cross-sectional view over Siberia). Only ACTM and CCAM simulations capture this feature to some extent over SUR. This is a clear indication that 10 out of 12 models underestimate vertical transport of surface emissions to the upper troposphere over Surgut due to deep cumulus convection during the JAS season. As discussed earlier, the higher $\mathrm{CH}_{4}$ values during May-June were under the influence of emissions over the Western Europe.

[20] The concentration at SAN sharply decreases with altitude in the lower troposphere, suggesting significant $\mathrm{CH}_{4}$ emission at this location, and the profiles above $3 \mathrm{~km}$ are relatively straight or slightly increasing in both seasons, indicating strong vertical motion in all seasons over this tropical site (Figures $3 \mathrm{~g}$ and $3 \mathrm{~h}$ ).

[21] When the convective activity is intense during the boreal summer, relatively straight vertical profiles are also observed at HAA, TGC, and other NH sites. The profiles at ocean sites HAA and RTA usually reveal characteristics of a background site with insignificant surface emissions around the site during all seasons. However, emission signals from Equatorial Asia/Western Pacific and Temperate Asia reach HAA during October-January and April-July, respectively, at $850 \mathrm{hPa}$ altitude (Figure S2). In addition, the Hawaiian Islands are located at the subtropical mixing barrier for chemical species [Miyazaki et al., 2008], causing greater seasonal variability at HAA than RTA in the lower troposphere (Table 3). Thus, the vertical profiles at HAA show a gradient in the JFM months despite being an ocean site due to the influence of northern hemispheric emissions and weak $\mathrm{OH}$ loss (Figure $3 \mathrm{e}$ ).

[22] The $\mathrm{CH}_{4}$ peak at 3-4 km during the JAS months over HAA (Figure 3f), typical of all years, is caused by the transport of high $\mathrm{CH}_{4}$ from Boreal Asia along the isentropic surfaces when the convective activity is low. Four models (GEOSChem, PCTM, IFS, and TM5) are able to simulate this feature to some extent. GEOS-Chem and PCTM are driven by the meteorological reanalysis from the Goddard Earth Observing System Data Assimilation System, whereas IFS and TM5 use ERA-Interim meteorology from the European Centre for Medium-Range Weather Forecasts (ECMWF). It is however unclear whether the better simulations by four models using GEOS and ECMWF reanalysis are due to the quality of meteorological products or from the representation of transport in the models. Sensitivity simulations using one of the models with both reanalysis products are needed to address this issue.

\subsection{Differences Between the Observations and Model Simulations}

[23] Figures $4 \mathrm{a}-4 \mathrm{~d}$ show the model-observation scatterplots at four different height ranges (black: $0.5-1.5 \mathrm{~km}$, blue:
1.5-3.0 km, green: $3.0-5.0 \mathrm{~km}$, and red: $5.0-7.0 \mathrm{~km}$ ) at sites SUR, THD, SGP, and HAA. The black diagonal line intersects at the coordinate origin with slope 1. Correlation coefficients $R$ between the model and observation time series are presented in Table S1. Several values, denoted by "0," did not satisfy a significance level of 0.05 based on the critical value for testing the null hypothesis $H_{0}$ of noncorrelation between two time series. Higher correlation coefficients in $3-5 \mathrm{~km}$ altitude range than that at $1-3 \mathrm{~km}$ altitude range suggest that the variance of model-observation difference is larger near the surface than in the free troposphere at most sites. This is primarily due to large emission signals as well as greater site representation error near the Earth's surface at synoptic time scales. These emissions are uncertain (e.g., monthly averages are used), which leads to larger model error near the surface. In contrast, the signals in the midtroposphere are dominated by transport processes.

[24] Figures $4 \mathrm{e}-4 \mathrm{~h}$ shows the frequency distribution of the model-observation difference at different seasons in winter (black: JFM), spring (blue: AMJ), summer (green: JAS), and autumn (red: OND) for the analysis years of 2001-2007. The model-observation difference at HAA in Figure 4h (also CAR, RTA, and ULB) falls within a small range of $\mathrm{CH}_{4}$ concentrations $( \pm 15 \mathrm{ppb}, 1 \sigma)$, and has a higher correlation (generally greater than 0.7 in Table S1, except NIES08i and TOMCAT) than at the other sites because of their location in the background marine environment (RTA and HAA) and inland (CAR and ULB) away from direct influence of continental sources (Figure 1). The model-observation differences at SUR, SGP, and THD (also SAN, LEF, HFM, and PFA) are as large as $100 \mathrm{ppb}$ for the high $\mathrm{CH}_{4}$ concentrations near the Earth's surface (Figure 4).

[25] The frequency distribution for the small modelobservation mismatches in the regions around HAA (Figure 4h), CAR, RTA, and ULB (not shown) shows little or no skewness. The low (high) skewness indicates small (large) seasonally varying model biases, while high kurtosis suggests that the model time series is well correlated with the observation time series. The skewness at THD is also small, and the kurtosis is low compared with the Gaussian distribution that is symmetric around 0 difference. On the other hand, SGP shows negative skewness, and the peaks of the population densities in spring and summer (blue and green histograms in Figure $4 \mathrm{~g}$ ) are negatively biased by about $20 \mathrm{ppb}$. Thus, Figures $4 \mathrm{c}$ and $4 \mathrm{~g}$ confirm that the models simulated relatively low $\mathrm{CH}_{4}$ concentrations compared to the observations at SGP. At SUR, the peak in summer (green in Figure 4e) is marginally skewed positive due to an overestimation of the modeled $\mathrm{CH}_{4}$ concentrations. These results suggest that the used $\mathrm{CTL} \mathrm{CH}_{4}$ emissions are too low (marginally high) around the SGP (SUR) site.

[26] These biases in simulated $\mathrm{CH}_{4}$ concentrations are unlikely to be due to transport model errors, because most models systematically show similar underestimations/ overestimations, and the performance of the TransCom- $\mathrm{CH}_{4}$ model ensemble has been found to be satisfactory at all other sites (e.g., Figures 4f, 4h, and S3). In addition, the lifetime of atmospheric $\mathrm{CH}_{4}$ is longer than 1 year in the troposphere, much longer compared to the transport or emission time scales around any given location [Patra et al., 2009a]. Thus, the model biases between sites within a hemisphere/continent are not likely to arise from uncertainty 
SAITO ET AL.: TRANSCOM-CH${ }_{4}$ MODELING OF AIRCRAFT OBSERVATIONS
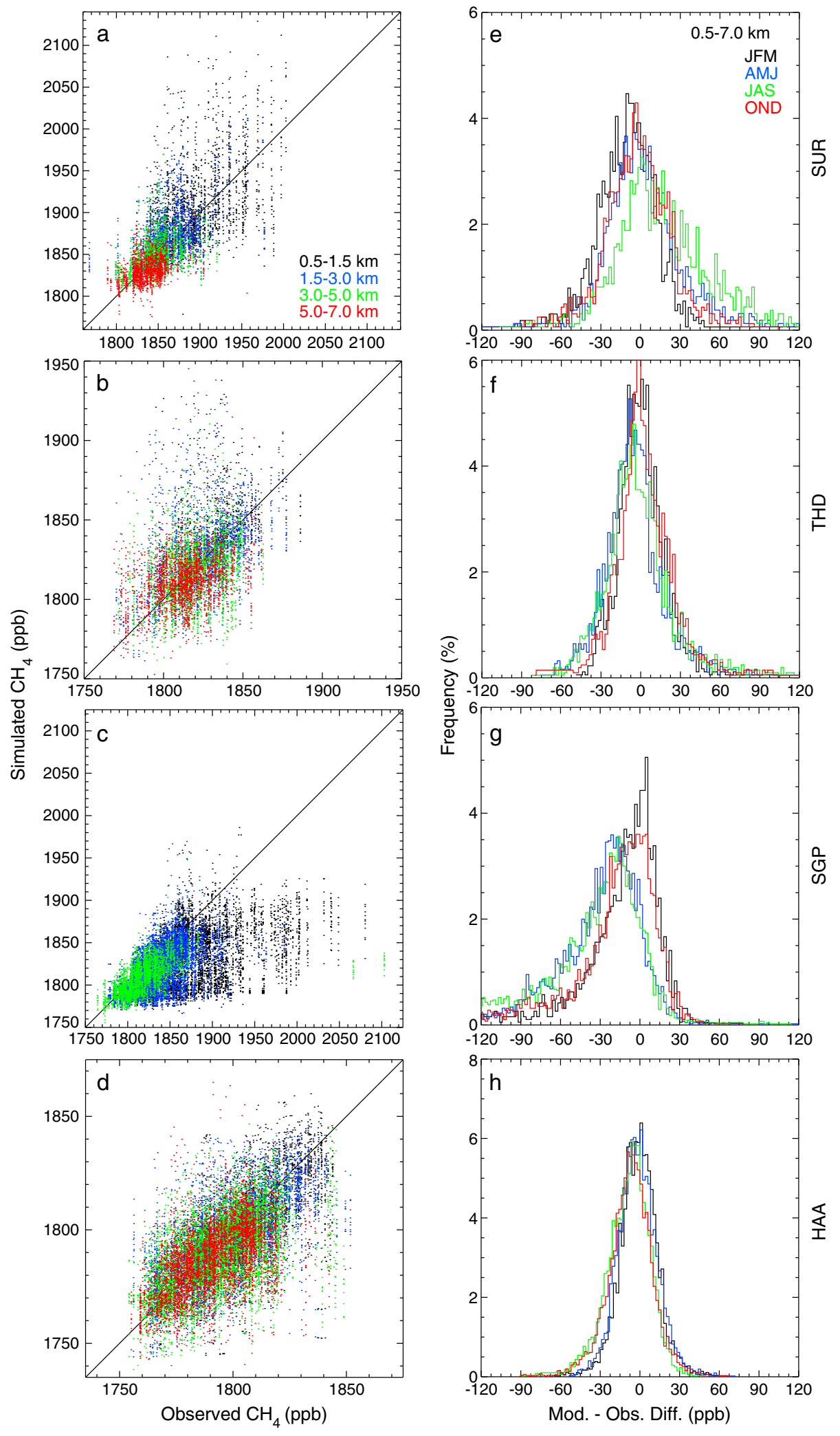

Figure 4. Correlations of observed and simulated $\mathrm{CH}_{4}$ concentrations for the analysis period (2001-2007) for four selected sites (SUR, THD, SGP, and HAA are organized from top to bottom row, respectively). The symbols within each panels of the left column correspond to different heights: (black) 0.5-1.5, (blue) 1.5-3.0, (green) 3.0-5.0, and (red) 5.0-7.0 km. Note that the axis range varies for Figures $4 \mathrm{a}-4 \mathrm{~d}$. The right panels show the frequency distribution of model-observation differences, averaged over all the CTMs and the altitude range 0.5-7.0 km for different seasons of (black) JFM, (blue) AMJ, (green) JAS, and (red) OND, where the class interval is $2 \mathrm{ppb}$. 


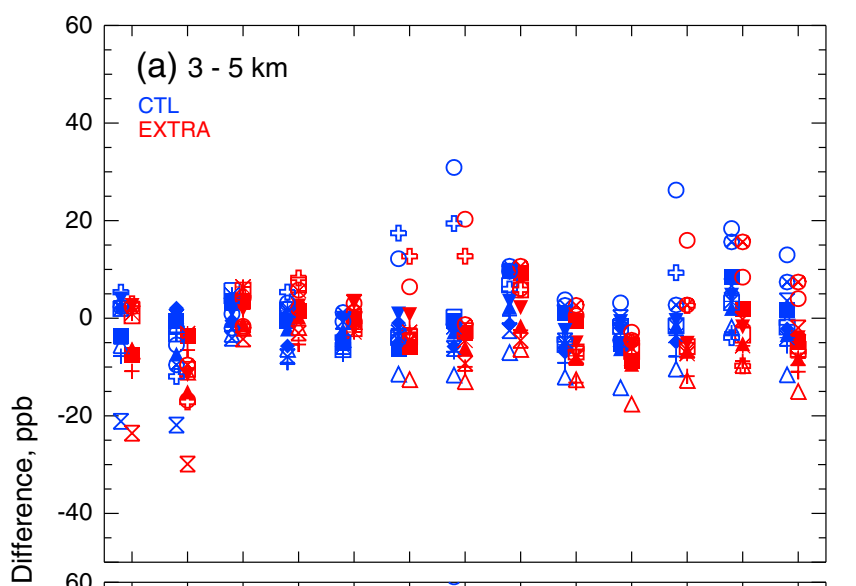

compared to CTL case in the Siberian region (Figure 1b). This suggests that the $\mathrm{CTL} \mathrm{CH}_{4}$ emissions around SUR are too high. Model simulations using either CTL or EXTRA emissions underestimate the observed $\mathrm{CH}_{4}$ concentrations at SAN, suggesting stronger emissions from the Amazon region or the vertical transport is faster in the models.

\subsection{Vertical, Latitudinal, and Longitudinal Gradients}

[27] We show the annual mean simulated and observed vertical gradients in Figure $5 \mathrm{c}$ and Table S2. Here the vertical gradient in $\mathrm{CH}_{4}$ profiles is defined as the difference of concentrations between the $1-3 \mathrm{~km}$ and $4-6 \mathrm{~km}$ heights.
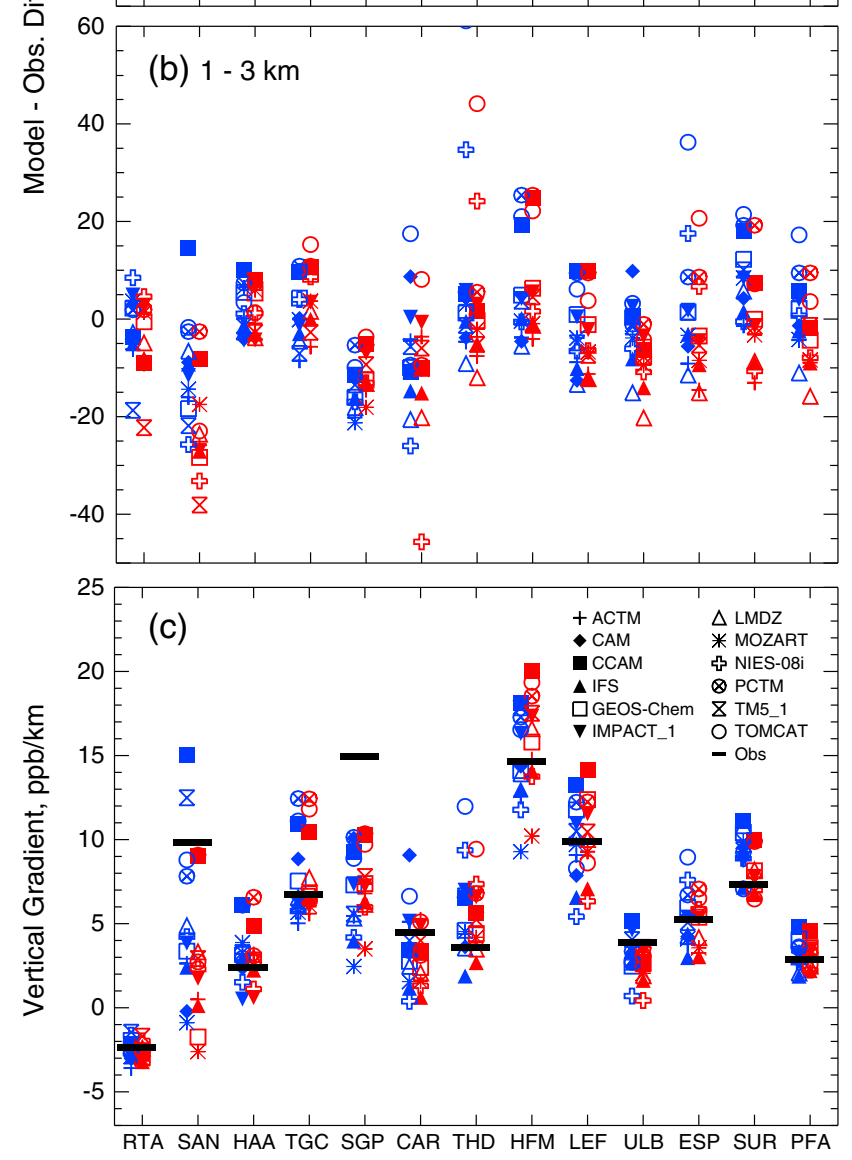

Figure 5. Differences between the observed and simulated $\mathrm{CH}_{4}$ concentrations averaged for the analysis years (2001-2007) are shown for the (a) middle troposphere $(3.0-5.0 \mathrm{~km})$ and (b) lower troposphere $(1.0-3.0 \mathrm{~km})$. All values are offset by the yearly average $\mathrm{CH}_{4}$ concentrations over $1-6 \mathrm{~km}$ at HAA before calculating the differences. Results corresponding to CTL and EXTRA fluxes are shown in blue and red, respectively. (c) Vertical gradients of the $\mathrm{CH}_{4}$ concentrations between 1-3 $\mathrm{km}$ and 4-6 $\mathrm{km}$ altitude ranges.

in $\mathrm{OH}$ abundance. Figures $5 \mathrm{a}$ and $5 \mathrm{~b}$ show mean modelobservation differences due to two emission scenarios used in this analysis, CTL (blue symbols) and EXTRA (red symbols), in the middle and lower tropospheric altitudes. Smaller model-observation differences are found at SUR in the EXTRA simulations, which has lower $\mathrm{CH}_{4}$ emissions

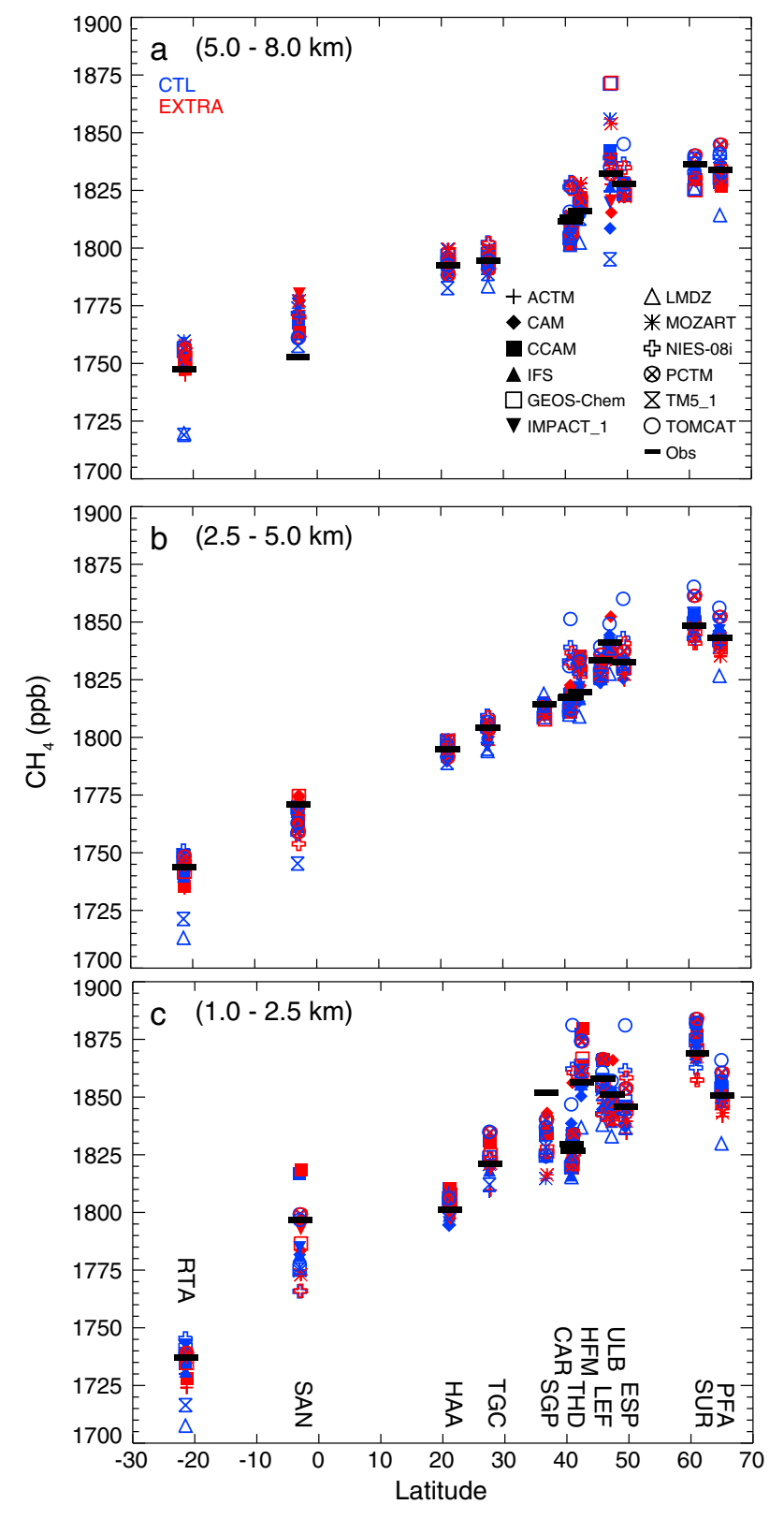

Figure 6. The CTM-simulated $\mathrm{CH}_{4}$ concentrations averaged in the (a) upper troposphere of 5.0-8.0 km, (b) middle troposphere of $2.5-5.0 \mathrm{~km}$, and (c) lower troposphere of $1.0-2.5 \mathrm{~km}$ for the analysis years (2001-2007) with the (blue) CTL and (red) EXTRA fluxes and (black) observed concentrations. 

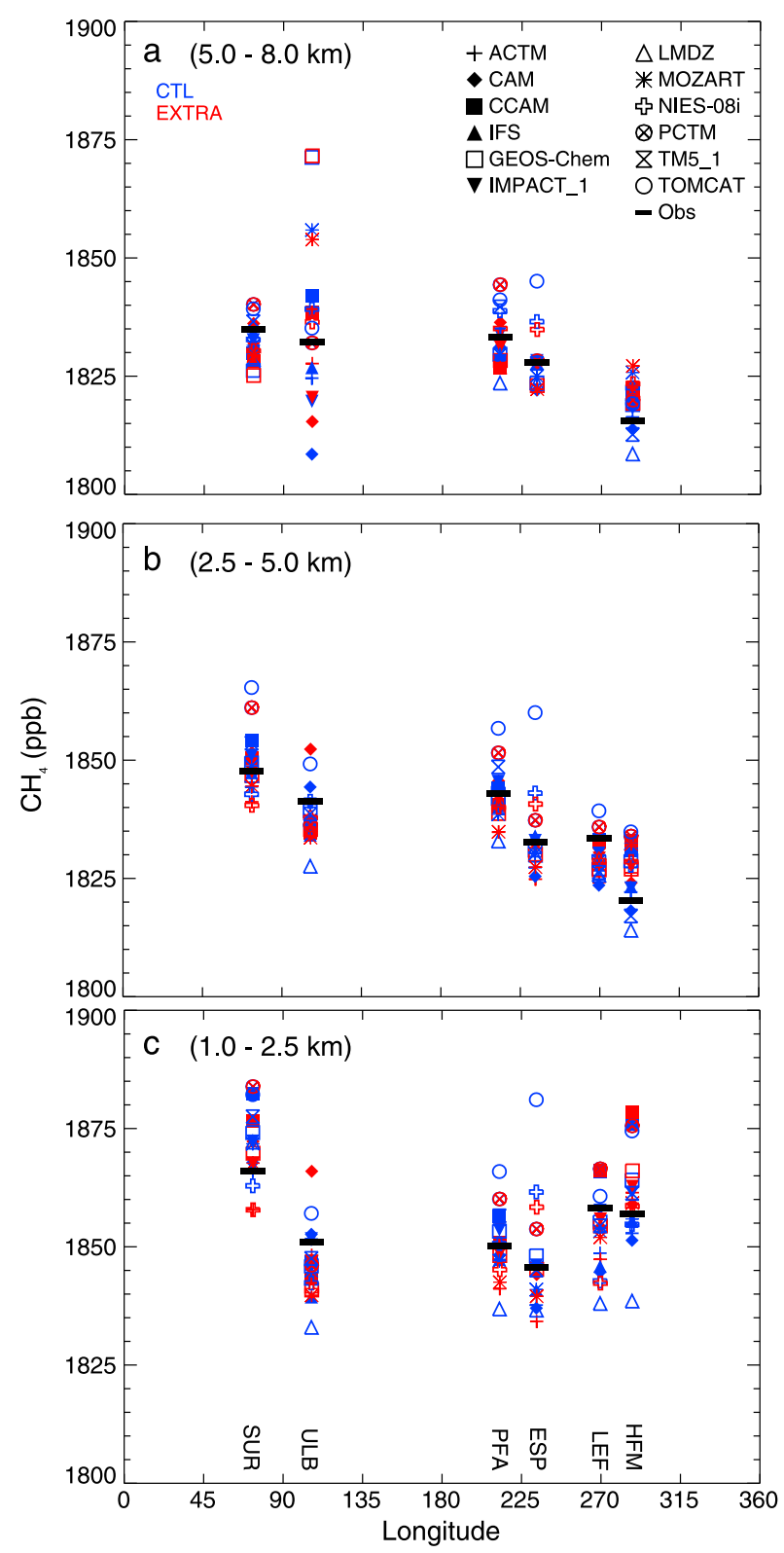

Figure 7. Longitudinal distribution of the CTM-simulated $\mathrm{CH}_{4}$ concentrations at sites higher than $42^{\circ} \mathrm{N}$ (i.e., SUR, $\mathrm{ULB}, \mathrm{PFA}, \mathrm{ESP}, \mathrm{LEF}$, and HFM from $0^{\circ} \mathrm{E}$ to $360^{\circ} \mathrm{E}$ ), averaged in the (a) upper troposphere of 5.0-8.0 km, (b) middle troposphere of 2.5-5.0 km, and (c) lower troposphere of $1.0-2.5 \mathrm{~km}$ for the analysis years (2001-2007) with the (blue) CTL and (red) EXTRA fluxes and (black) observed concentrations.

The simulated vertical gradients are generally within $5 \mathrm{ppb}$ of the observed gradients at the oceanic sites (i.e., RTA and HAA), most of the coastal sites (i.e., TGC, ESP and PFA), and some of the continental sites (i.e., CAR, SUR, and ULB). The differences between simulated and observed vertical gradients are more than $5 \mathrm{ppb}$ at SAN, SGP, LEF, and HFM (continental sites). The model-observation differences are systematically biased positive and negative, respectively, at SUR/THD and SAN/SGP, for most of the transport models. These results are consistent with overestimation and underestimation of simulated concentrations compared to observations in the lower troposphere at SUR and SGP, respectively (Figures $4 \mathrm{a}$ and $4 \mathrm{e}$ and Figures $4 \mathrm{c}$ and $4 \mathrm{~g}$ ). These systematic model-observation biases are thus likely to be caused by regional emissions in the CTL scenario rather than errors in $\mathrm{CH}_{4}$ loss (longer than 1 year lifetime due to $\mathrm{OH}$ reaction) and model transport. By using EXTRA emissions (red symbols), the simulated vertical gradients worsen for the sites SAN, HFM, and ULB, in comparison with the observations, but improve slightly over SUR.

[28] Figure 6 shows comparisons of the simulated and observed latitudinal distributions of $\mathrm{CH}_{4}$ concentrations among all sites at different height ranges (1.0-2.5, 2.5-5.0, and $5.0-8.0 \mathrm{~km})$. The measured $\mathrm{CH}_{4}$ concentrations increase from $\mathrm{SH}$ to $\mathrm{NH}$ between $20^{\circ} \mathrm{S}$ and $50^{\circ} \mathrm{N}$ in the troposphere, at near linear rates of $1.4 \mathrm{ppb} / \mathrm{deg}$ at $1.0-2.5 \mathrm{~km}$, $1.3 \mathrm{ppb} / \mathrm{deg}$ at $2.5-5.0 \mathrm{~km}$, and $1.2 \mathrm{ppb} / \mathrm{deg}$ at $5.0-8.0 \mathrm{~km}$. These values are generally well simulated by the models using both CTL and EXTRA emission scenarios. The differences in latitudinal gradient are mainly due to the decrease in $\mathrm{CH}_{4}$ concentrations with height in the $\mathrm{NH}$, e.g., the upper tropospheric concentration in the $\mathrm{NH}$ high-latitude sites is $\sim 30 \mathrm{ppb}$ lower than the lower tropospheric values. The agreement between model and observations is best for the $2.5-5.0 \mathrm{~km}$ altitude range, where the standard deviation of model-observation differences is $\sim 5 \mathrm{ppb}$ (see also Table S3). Although model uncertainty in the free troposphere is usually small, variance among the models at ULB at $5 \mathrm{Alkm}$ is larger than that in the other sites. This is presumably due to the long-range transport of European and Siberian $\mathrm{CH}_{4}$ emission signals to ULB as discussed earlier (section 3.1). The smaller (1.2 ppb/deg) interhemispheric gradient at 5 intkm, compared to that at 2.5-5.0 km heights, indicates that the $\mathrm{CH}_{4}$ in the $\mathrm{NH}$ upper troposphere is more readily transported to the $\mathrm{SH}$. This effect can be seen as the higher $\mathrm{CH}_{4}$ concentration in the upper troposphere at RTA than in the lower troposphere. A higher concentration in the $\mathrm{SH}$ upper troposphere compared to that in the lower troposphere is also observed for nonreactive species, such as $\mathrm{CO}_{2}$ and $\mathrm{SF}_{6}$ [Nakazawa et al., 1991; Miyazaki et al., 2008; Patra et al., 2009b; Sawa et al., 2012]. The role of surface emissions on meridional gradient weakens rapidly with increasing height between $1.0-2.5$ and $2.5-5.0 \mathrm{~km}$ (Figures $6 \mathrm{~b}$ and $6 \mathrm{c}$ ).

[29] Figure 7 shows the variation of $\mathrm{CH}_{4}$ with longitude for sites north of $42^{\circ} \mathrm{N}$ (i.e., SUR, ULB, PFA, ESP, LEF, and HFM) in the same height ranges as Figure 6 in order to investigate zonal $\mathrm{CH}_{4}$ transport and vertical propagation driven by surface $\mathrm{CH}_{4}$ emissions from North America, Europe, and Siberia. The lower tropospheric variations in $\mathrm{CH}_{4}$ are mainly linked to stronger emissions around SUR and HFM compared to those around ULB and ESP. The $\mathrm{CH}_{4}$ concentrations in the middle troposphere clearly have an eastward decreasing trend in observation and models for both CTL and EXTRA emissions (about $-0.1 \mathrm{ppb} / \mathrm{deg}$ from the prime meridian to eastward; Figure $7 \mathrm{~b}$ ). The high $\mathrm{CH}_{4}$ concentration in the lower troposphere over Siberia (Figure 7c) is diluted through mixing and reduces the difference between average values at SUR and other sites (except HFM) at the 5-8 km height range (Figure 7a). This behavior is seen consistently for measurements and model using both the emission scenarios. Apparently, the $\mathrm{CH}_{4}$-rich air over the Eurasian continent in the upper troposphere 


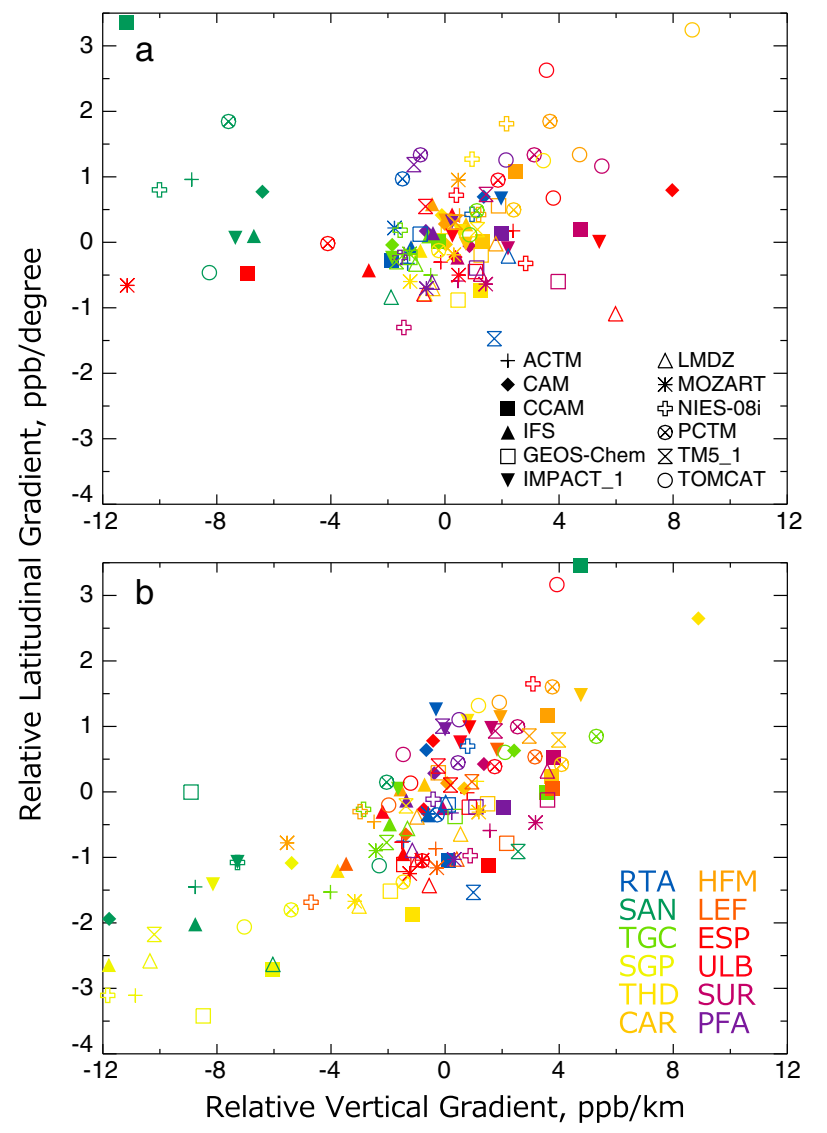

Figure 8. $\mathrm{CH}_{4}$ vertical gradients $(\mathrm{ppb} / \mathrm{km})$ are plotted against the latitudinal gradients in $\mathrm{CH}_{4}$ (ppb/deg) between the sites within two altitude ranges: (a) $3.0-5.0 \mathrm{~km}$ and (b) $0.5-2.5 \mathrm{~km}$. All data are averaged for the period 2001-2007, and the results for the CTL flux are shown. The symbol for each model is color-coded for the gradients between each site and the reference site HAA. Both gradients are plotted as a difference relative to the measured gradients.

extends to the western side of the North American continent (PFA and ESP) as suggested by the longitude-pressure cross-sectional plots (refer to Figure S2). The air in the upper troposphere on the eastern side of northern United States mostly originates at about $40^{\circ} \mathrm{N}$ over the Pacific Ocean, except for the winter months, giving relatively low $\mathrm{CH}_{4}$ concentrations at HFM. These results are generally consistent with Xiong et al. [2010], but our understanding is improved significantly on the longitudinal variations in upper tropospheric $\mathrm{CH}_{4}$ by including a greater number of vertical profile measurements.

\subsection{Correlation of Latitudinal and Vertical Transports}

[30] The overestimations or underestimations of latitudinal gradients of long-lived atmospheric species simulated by models, compared to the measurements, are thought to be linked with the vertical concentration gradients of those species [Denning et al., 1999]. To explore this hypothesis further, we show scatterplots of vertical gradients at each site and latitudinal gradient, with reference to HAA, within two altitude ranges $3-5$ and $0.5-2.5 \mathrm{~km}$ (Figure 8 ). Both gradients are plotted as the differences relative to the measured gradients, showing which models overestimate or underestimate the vertical and latitudinal gradients. Relative gradients are chosen to remove biases in simulated concentrations with respect to measurement, which are often greater than the measured gradients. In the middle troposphere $(3-5 \mathrm{~km})$, relative vertical and latitudinal gradients are scattered in the approximate ranges of -10 to $+7 \mathrm{ppb} / \mathrm{km}$ and -1.5 to $+2.0 \mathrm{ppb} / \mathrm{deg}$, respectively. Loose correlation between vertical and horizontal gradients suggests that the interhemispheric transport is relatively insensitive to the local/regional vertical profile of $\mathrm{CH}_{4}$ in the $3-5 \mathrm{~km}$ altitude range and that the transport in the models is similar. However, the relative latitudinal gradients are apparently proportional to the relative vertical gradient in the lower troposphere $(0.5-2.5 \mathrm{~km})$, suggesting that the vertical transport of emission signals through the lower troposphere plays a critical role in determining interhemispheric gradients near the Earth's surface.

[31] A schematic representation of the relationship between vertical and interhemispheric transports is shown in Figure 9a. The monthly mean modeled vertical gradients in the $\mathrm{NH}$ are calculated as the difference between the $\mathrm{CH}_{4}$ concentrations between 900 and $500 \mathrm{hPa}$ altitudes. Values are also averaged over all the model grid cells between $30^{\circ} \mathrm{N}$ and $50^{\circ} \mathrm{N}$ for 2007 . Average latitudinal gradients are calculated as the difference between mean $\mathrm{CH}_{4}$ for $\mathrm{SH}$ $\left(50^{\circ} \mathrm{S}-30^{\circ} \mathrm{S}\right)$ and $\mathrm{NH}\left(30^{\circ} \mathrm{N}-50^{\circ} \mathrm{N}\right)$. Annual mean values of the interhemispheric and $\mathrm{NH}$ vertical gradients in $\mathrm{CH}_{4}$ show a compact relationship (black symbols). The seasonal variations in this relationship are mainly controlled by the vertical transports and the emission and loss rates of $\mathrm{CH}_{4}$. In July, both the latitudinal and $\mathrm{NH}$ vertical gradients are smaller than those in the other seasons because of faster loss rates in the $\mathrm{NH}$ and lower loss rates in the $\mathrm{SH}$ as well as stronger vertical mixing in the $\mathrm{NH}$, despite high emission rates in the $\mathrm{NH}$. In October, the $\mathrm{NH}$ vertical gradients are the largest among all seasons (high emission rate, low loss scenario), although the latitudinal gradients do not increase significantly. In January, the midtropospheric $\mathrm{CH}_{4}$ concentrations reach a seasonal high because of accumulation in the NH through autumn and early winter (low emission, very low loss scenario, and weaker vertical mixing). This condition leads to the largest interhemispheric gradients in January.

[32] The interactions between vertical and latitudinal gradients in $\mathrm{CH}_{4}$ (also valid for tracers in the troposphere with lifetimes greater than the interhemispheric transport time of about 1.3 years; see Figure $\mathrm{S} 5$ for $\mathrm{SF}_{6}$ results) are schematically depicted in Figure $9 \mathrm{~b}$. Based on our analysis, we hypothesize that (1) vertical transport is driven by the strength of convection as well as turbulent mixing in the boundary layer (BL) and (2) meridional gradients depend mainly on the mixing in the BL for sites close to emissions and on the horizontal advection scheme for the remote/ background sites. However, there is interaction between the turbulent mixing, convection, and advection processes in the model. A study using ACTM [Patra et al., 2009b] suggested that the turbulent mixing transports emission signals to the $900-800 \mathrm{mb}$ height layer, and the convective processes transport species from the BL to the middle and upper troposphere (MUT). Most of the interhemispheric transport due to advection occurs at higher altitudes. Thus, a model transport with weaker turbulent mixing and 

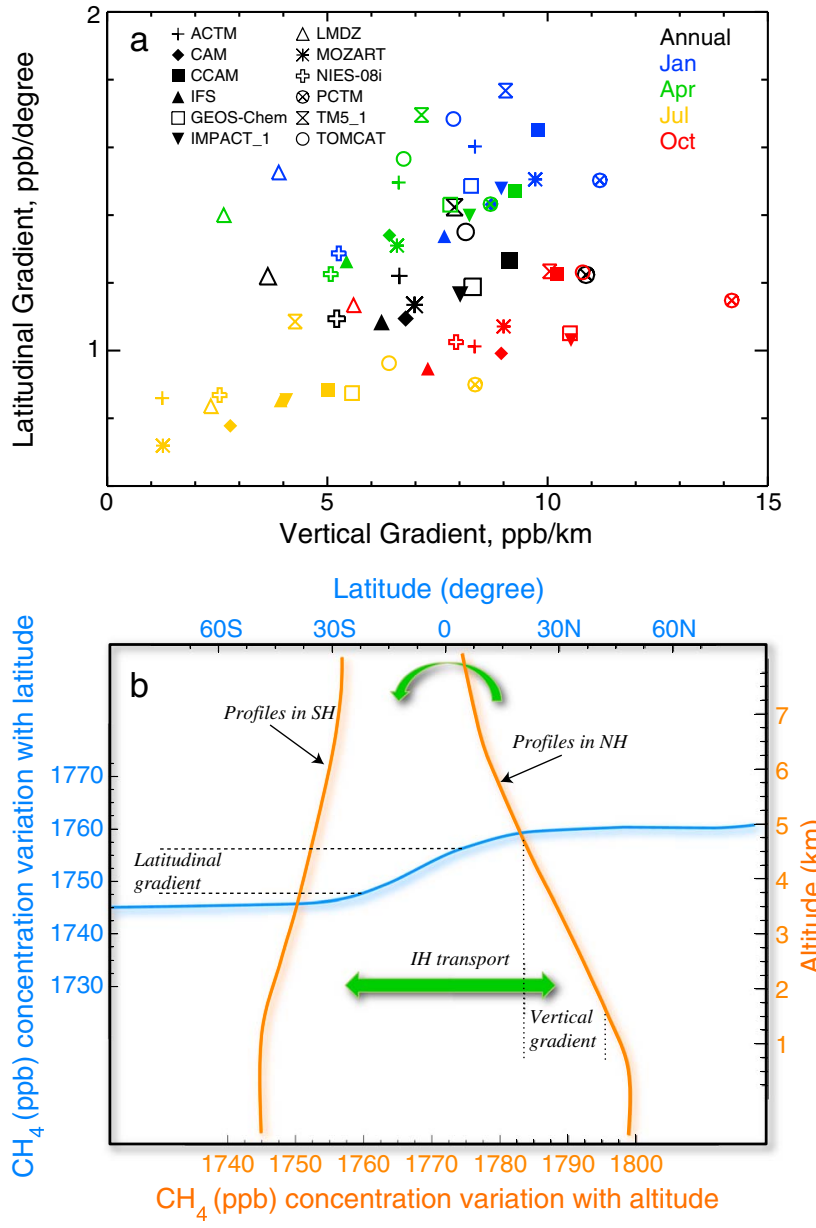

Figure 9. (a) Modeled vertical gradients in the $\mathrm{NH}$ between $900 \mathrm{hPa}(\sim 1 \mathrm{~km})$ and $500 \mathrm{hPa}(\sim 5 \mathrm{~km})$ in the latitude range of $30^{\circ} \mathrm{N}-50^{\circ} \mathrm{N}$ are plotted versus the modeled latitudinal gradients between the $\mathrm{NH}\left(30^{\circ} \mathrm{N}-50^{\circ} \mathrm{N}\right)$ and the $\mathrm{SH}$ $\left(50^{\circ} \mathrm{S}-30^{\circ} \mathrm{S}\right)$, averaged over the height range of 900 $500 \mathrm{hPa}(\sim 1.0-5.5 \mathrm{~km})$. Results are shown for different months, representing boreal winter, spring, summer, and autumn (January, April, July, and October, respectively) and for annual mean. (b) A schematic of the relationship between the vertical and interhemispheric transports is depicted in the lower panel.

convection has a tendency toward steeper meridional gradient in the simulated concentrations at lower altitudes but not at higher altitudes $(6-8 \mathrm{~km})$.

[33] As discussed in Patra et al. [2011a] and shown in Figure 9a, the TM5 model produces one of the largest latitudinal gradients in $\mathrm{CH}_{4}$ among all the models that participated in the TransCom- $\mathrm{CH}_{4}$ experiment. However, we find in this study that the NH vertical gradients simulated by TM5 are not the largest. The latitudinal gradients shown in Figure 6 suggest that the stronger gradients in the TM5 simulations are mainly due to low $\mathrm{SH}$ concentrations compared to other models, likely to be caused by slower meridional transport. PCTM produced the largest vertical gradients below 1-2 km (refer to Figures 3 and 9a), most likely due to trapping of emissions within the planetary boundary layer. However, the simulated interhemispheric gradients are not extreme because stronger vertical gradients for PCTM in both the hemispheres (Figure 5c) result in an interhemispheric gradient that is close to the multimodel average. All other models suggest that a stronger vertical gradient in $\mathrm{NH}$ troposphere corresponds to a stronger interhemispheric gradient in $\mathrm{CH}_{4}$ concentrations.

\section{Conclusions}

[34] We assessed zonal, meridional, and vertical transports of tropospheric $\mathrm{CH}_{4}$ using the chemical transport models (CTMs) and two emission scenarios (CTL and EXTRA) in comparison with aircraft measurements. The model-model difference is large near the surface in source regions and during strong convection and small in the middle/upper troposphere and over the marine background regions. The model-observation differences are controlled predominantly by the model transport and the surface emission rather than the loss rates of $\mathrm{CH}_{4}$. At most sites, the simulated concentrations vary around the observed values, while at three sites, the model results are systematically biased relative to the observed value. The positive (at Surgut, Russia) and negative (at South Great Plain, United States, and Santarem, Brazil) biases, systematic for most models, can be attributed to higher and lower $\mathrm{CH}_{4}$ emissions as estimated in the CTL case. These model-observation comparison results are generally consistent for simulations using both the emission scenarios, CTL or EXTRA (except for Surgut, where simulations using lower emissions over the Siberian region, as in EXTRA, showed better model-observation agreements).

[35] Observed $\mathrm{CH}_{4}$ profiles show near-zero vertical gradients above $3 \mathrm{~km}$, where models indicate that the convective activity is the primary driver of mixing (all seasons over the Amazon and summer months in the higher latitudes), and elevated concentrations in the upper troposphere region, when measurements are available over Surgut. In contrast, stronger decreases with altitudes above $3 \mathrm{~km}$ are observed in the middle- and high-latitude land regions, where the anthropogenic emissions are intense (e.g., TGC, HFM, and SUR) compared to the lower emissions over the background marine sites (e.g., HAA and ULB). The model-model differences are found to be greatest at sites located over intense emission regions for the height below $3 \mathrm{~km}$. In the middle and upper troposphere (MUT), greater model-model differences are found over the regions with stronger convective activities (e.g., SAN and NH sites during summer). These two results suggest that the turbulent mixing (acting below $3 \mathrm{~km}$ ) and deep cumulus convection (acting in the MUT region) parameterizations in the CTMs are less similar compared to the other transport processes, such as advection (except for one model).

[36] Interhemispheric gradients of the simulations and observations were $1.5 \pm 0.1$ and $1.3 \pm 0.2 \mathrm{ppb} / \mathrm{deg}$ for the lower and middle troposphere, respectively. In an effort to understand the origin of model-model differences in interhemispheric gradients, we have shown scatterplots of vertical gradients in $\mathrm{CH}_{4}$ concentrations between lower and middle troposphere and latitudinal gradients between the two hemispheres. Generally, the models that produced higher vertical gradients for $\mathrm{CH}_{4}$ (and also $\mathrm{SF}_{6}$ ) concentrations also produced steeper interhemispheric gradients near the surface. In models with underestimated vertical mixing mainly due to boundary-layer turbulent mixing and parameterized 
convection, tracers tend to get trapped near the sources in the lower troposphere. In this case, the model is likely to overestimate meridional gradients in tracer concentrations, resulting from relative inefficient advective transport between the hemispheres (except for two exceptions in PCTM and TM5).

[37] Acknowledgments. This work was supported by JSPS/MEXT KAKENHI-A (grant 22241008). A. Fraser was supported by the UK Natural Environment Research Council National Centre for Earth Observation. We acknowledge the work of J. McGregor and M. Thatcher in the development of CCAM. CCAM simulations were undertaken as part of the Australian Climate Change Science Program and used the NCI National Facility in Canberra, ACT, Australia. R. Prinn and M. Rigby were supported by NASA-AGAGE grants NNX07AE89G and NNX11AF17G to MIT. M. Rigby was also supported by a NERC Advanced Fellowship. The TOMCAT work at the University of Leeds was supported by NERC/NCEO. The research leading to the IFS results has received funding from the European Community's Seventh Framework Programme [FP7 THEME (SPA.2011.1.5-02)] under grant 283576 in the context of the MACC-II project (Monitoring Atmospheric Composition and Climate-Interim Implementation). We sincerely thank all three anonymous reviewers for critical evaluation and providing very helpful comments and suggestions for improving the article.

\section{References}

Beck, V., et al. (2012), Methane airborne measurements and comparison to global models during BARCA, J. Geophys. Res., 117, D15310, doi:10.1029/2011JD017345.

Belikov, D., S. Maksyutov, T. Miyasaka, T. Saeki, R. Zhuravlev, and B. Kiryushov (2011), Mass-conserving tracer transport modelling on a reduced latitude-longitude grid with NIES-TM, Geosci. Model Dev., 4, 207-222, doi:10.5194/gmd-4-207-2011.

Bergamaschi, P., et al. (2009), Inverse modeling of global and regional $\mathrm{CH}_{4}$ emissions using SCIAMACHY satellite retrievals, J. Geophys. Res., 114, D22301, doi:10.1029/2009JD012287.

Bian, H., S. R. Kawa, M. Chin, S. Pawson, Z. Zhu, P. Rasch, and L. Wu (2006), A test of the representation of convective cloud transport in a model of $\mathrm{CO}_{2}$ transport, Tellus, 58B(5), 463-475, doi:10.1111/j.1600-0889.2006.00212.X.

Corbin, K. D., and R. M. Law (2011), Extending atmospheric $\mathrm{CO}_{2}$ and tracer capabilities in ACCESS, CAWCR Tech. Rep. 35, The Centre for Australian Weather and Climate Research, ISBN:978-1-921826-177, Aspendale.

Denning, A. S., et al. (1999), Three-dimensional transport and concentration of $\mathrm{SF}_{6}$ : A model intercomparison study (TransCom-2), Tellus, $51 B$, 266-297, 1999.

Dlugokencky, E. J., R. C. Myers, P. M. Lang, K. A. Masarie, A. M. Crotwell, K. W. Thoning, B. D. Hall, J. W. Elkins, and L. P. Steele (2005), Conversion of NOAA atmospheric dry air $\mathrm{CH}_{4}$ mole fractions to a gravimetrically prepared standard scale, J. Geophys. Res., 110, D18306, doi:10.1029/ 2005JD006035.

Chipperfield, M. P. (2006), New version of the TOMCAT/SLIMCAT off-line chemical transport model: Intercomparison of stratospheric tracer experiments, Q. J. R. Meteorol. Soc., 132, 1179-1203, doi:10.1256/qj.05.51.

Emmons, L. K., et al. (2010), Description and evaluation of the Model for Ozone and Related chemical Tracers, version 4 (MOZART-4), Geosci. Model Dev., 3, 43-67, doi:10.5194/gmd-3-43-2010.

Fraser, A., C. Chan Miller, P. I. Palmer, N. M. Deutscher, N. B. Jones, and D. W. T. Griffith (2011), The Australian methane budget: interpreting surface and train-borne measurements using a chemistry transport model, J. Geophys. Res., 116, D20306, doi:10.1029/2011JD015964.

Fung, I., J. John, J. Lerner, E. Matthews, M. Prather, L. P. Steele, and P. Fraser (1991), Three-dimensional model synthesis of the global methane cycle, J. Geophys. Res., 96(D7), 13,033-13,065.

Gatti, L. V., J. B. Miller, M. T. S. D'Amelio, A. Martinewski, L. S. Basso, M. E. Gloor, S. Wofsy, and P. Tans (2010), Vertical profiles of $\mathrm{CO}_{2}$ above eastern Amazonia suggest a net carbon flux to the atmosphere and balanced biosphere between 2000 and 2009, Tellus, 62B, 581-594, doi:10.1111/j.1600-0889.2010.00484.X,

Gent, P. R., S. G. Yeager, R. B. Neale, S. Levis, and D. A. Bailey (2009), Improvements in a half degree atmosphere/land version of the CCSM, Clim. Dyn., 79, 25-58, doi:10.1007/s00382-009-0614-8.

Graedel, T. E., and P. J. Crutzen (1993), Atmospheric change: An Earth system perspective, pp. 446, Freeman, New York, ISBN:0716723344.

Hourdin, F., et al. (2006), The LMDZ4 general circulation model: climate performance and sensitivity to parametrized physics with emphasis on tropical convection, Clim. Dyn., 27, 787-813, doi:10.1007/s00382-0060158-0.
Ito, A., and M. Inatomi (2012), Use and uncertainty evaluation of a processbased model for assessing the methane budget of global terrestrial ecosystems, Biogeosciences, 9, 759-773, doi:10.5194/bg-9-759-2012.

Kawa, S. R., D. J. Erickson III, S. Pawson, and Z. Zhu (2004), Global $\mathrm{CO}_{2}$ transport simulations using meteorological data from the NASA data assimilation system, J. Geophys. Res., 109, D18312, doi:10.1029/ 2004JD004554.

Krol, M. C., S. Houweling, B. Bregman, M. van den Broek, A. Segers, P. vanVelthoven, W. Peters, F. J. Dentener, and P. Bergamaschi (2005), The two-way nested global chemistry-transport zoom model TM5: Algorithm and applications, Atmos. Chem. Phys., 5, 417-432, doi:10.5194/ acp-5-417-2005.

Law, R. M., E. A. Kowalczyk, and Y.-P. Wang (2006), Using atmospheric $\mathrm{CO}_{2}$ data to assess a simplified carbon-climate simulation for the 20th century, Tellus, Ser. B, 53, 427-437, doi:10.1111/j.1600-0889.2006.00198.X.

Law, R. M., et al. (2008), TransCom model simulations of hourly atmospheric $\mathrm{CO}_{2}$ : Experimental overview and diurnal cycle results for 2002, Global Biogeochem. Cycles, 22, GB3009, doi:10.1029/ 2007GB003050.

Machida, T., et al. (2001), Temporal and spatial variations of atmospheric $\mathrm{CO}_{2}$ mixing ratio over Siberia, paper presented at the Sixth International $\mathrm{CO}_{2}$ Conference, Sendai, Japan.

Miyazaki, K., P. K. Patra, M. Takigawa, T. Iwasaki, and T. Nakazawa (2008), Global-scale transport of carbon dioxide in the troposphere, J. Geophys. Res., 113, D15301, doi:10.1029/2007JD009557.

Nakazawa, T., K. Miyashita, S. Aoki, and M. Tanaka (1991), Temporal and spatial variations of upper tropospheric and lower stratospheric carbon dioxide, Tellus, Ser. B, 43, 106-117.

Olivier, J. G. J., and J. J. M. Berdowski (2001), Global emissions sources and sinks, in The Climate System, edited by J. Berdowski, R. Guicherit, and B. J. Heij, pp. 33-78, A. A. Balkema Publishers/Swets \& Zeitlinger Pub., Lisse, Netherlands, ISBN:9058092550.

Patra, P. K., et al. (2009a), Growth rate, seasonal, synoptic, diurnal variations and budget of methane in lower atmosphere, J. Meteorol. Soc. Jpn., 87(4), 635-663, doi:10.2151/jmsj.87.635.

Patra, P. K., M. Takigawa, G. S. Dutton, K. Uhse, K. Ishijima, B. R. Lintner, K. Miyazaki, and J. W. Elkins (2009b), Transport mechanisms for synoptic, seasonal and interannual $\mathrm{SF}_{6}$ variations and "age" of air in the troposphere, Atmos. Chem. Phys., 9, 1209-1225, doi:10.5194/acp-91209-2009.

Patra, P. K., et al. (2011a), TransCom model simulations of $\mathrm{CH}_{4}$ and related species: Linking transport, surface flux and chemical loss with $\mathrm{CH}_{4}$ variability in the troposphere and lower stratosphere, Atmos. Chem. Phys., 11, 12,813-12,837, doi:10.5194/acp-11-12813-2011.

Patra, P. K., Y. Niwa, T. J. Schuck, C. A. M. Brenninkmeijer, T. Machida, H. Matsueda, and Y. Sawa (2011b), Carbon balance of South Asia constrained by passenger aircraft $\mathrm{CO}_{2}$ measurements, Atmos. Chem. Phys., 11, 4163-4175, doi:10.5194/acp-11-4163-2011.

Rotman, D. A., et al. (2004), IMPACT, the LLNL 3-D global atmospheric chemical transport model for the combined troposphere and stratosphere: Model description and analysis of ozone and other trace gases, J. Geophys. Res., 109, D04303, doi:10.1029/2002JD003155.

Sawa, Y., T. Machida, and H. Matsueda (2012), Aircraft observation of the seasonal variation in the transport of $\mathrm{CO}_{2}$ in the upper atmosphere, J. Geophys. Res., 117, D05305, doi:10.1029/2011JD016933.

Spivakovsky, C., et al. (2000), Three-dimensional climatological distribution of tropospheric OH: Update and evaluation, J. Geophys. Res., 105(D7), $8931-8980$

Stephens, B. B., et al. (2007), Weak northern and strong tropical land carbon uptake from vertical profiles of atmospheric $\mathrm{CO}_{2}$, Science, 316(5832), 1732-1735, doi:10.1126/science.1137004.

Tans, P. P., et al. (1996), Carbon Cycle (Group Report), Climate Monitoring and Diagnostics Laboratory, No. 23, Summary Report 1994-1995, edited by D. J. Hoffman, J. T. Peterson, and R. M. Rosson, http://www.esrl.noaa.gov/gmd/publications/annrpt23/contents.html, U.S. Department of Commerce, Boulder, Colo.

van der Werf, G. R., J. T. Randerson, L. Giglio, G. J. Collatz, P. S Kasibhatla, and A. F. Arellano Jr. (2006), Interannual variability in global biomass burning emissions from 1997 to 2004, Atmos. Chem. Phys., 6, 3423-3441, doi:10.5194/acp-6-3423-2006.

Xiong, X., C. D. Barnet, Q. Zhuang, T. Machida, C. Sweeney, and P. K. Patra (2010), Mid-upper tropospheric methane in the high Northern Hemisphere: Spaceborne observations by AIRS, aircraft measurements, and model simulations, J. Geophys. Res., 115, D19309, doi:10.1029/ 2009JD013796.

Zhou, L. X., D. Kitzis, and P. P. Tans (2009), Report of the fourth WMO round-robin reference gas intercomparison, 2002-2007, in Report of the 14th WMO meeting of Experts on Carbon Dioxide Concentration and Related Tracer Measurement Techniques, edited by T. Laurila, pp. 40-43, Helsinki, Finland, September 10-13, 2007, WMO/GAWReport No. 186. 